\title{
A New Decision Support Framework with Picture Fuzzy Information: Comparison of Video Conferencing Platforms for Higher Education in India
}

\author{
Sanjib Biswas, ${ }^{1}$ Dragan Pamucar $\mathbb{D D}^{2},{ }^{2}$ Paramita Chowdhury, ${ }^{1}$ and Samarjit Kar $^{3}$ \\ ${ }^{1}$ Decision Sciences and Operations Management Area, Calcutta Business School, South 24 Parganas, Bishnupur 743503, \\ West Bengal, India \\ ${ }^{2}$ Department of Logistics, Military Academy, University of Defence, Belgrade 11000, Serbia \\ ${ }^{3}$ Department of Mathematics, National Institute of Technology, Durgapur 713209, West Bengal, India \\ Correspondence should be addressed to Dragan Pamucar; dragan.pamucar@va.mod.gov.rs
}

Received 24 September 2021; Revised 10 December 2021; Accepted 15 December 2021; Published 30 December 2021

Academic Editor: Ya Jia

Copyright (C) 2021 Sanjib Biswas et al. This is an open access article distributed under the Creative Commons Attribution License, which permits unrestricted use, distribution, and reproduction in any medium, provided the original work is properly cited.

\begin{abstract}
The purpose of this paper is to present a novel extension of a very recently developed multicriteria decision making (MCDM) algorithm known as the preference ranking on the basis of ideal-average distance (PROBID) method in a picture fuzzy (PF) environment. We use the full consistency method (FUCOM) with picture fuzzy numbers (PFNs) for deriving the criteria weights. We attempt to apply our proposed model for addressing a real-life complex decision making problem in social science research that gets influenced by the dynamics of discrete human behaviors. We compare eight popular video conferencing (VC) tools used for teaching-learning and meeting purposes in India using our novel integrated multicriteria decision making (MCDM) framework of FUCOM-PROBID with PF information. The criteria have been derived using the theoretical foundation of usability and user experience (UX). Based on the opinion of the decision makers (DM) or users who took part in the study, we find that ease of operations, compatibility with multiple systems and devices, quality of the voice, and video transmission and features are given more emphasis while Zoom, Microsoft Teams, and Google Meet are found to be preferable options to the users. The result of the proposed model shows stability and robustness as evident from the validation test and sensitivity analysis.
\end{abstract}

\section{Introduction}

The novel coronavirus has started spreading since January 2020 from Wuhan, China. This coronavirus has resulted in panic and fear among the people and shuttered all facets of the socioeconomic and cultural environment across the globe. However, over the ages, it is a proven fact that education is an essential requirement for protecting the humanity and development of society and nation. Even amidst the recent pandemic, the Governments of various countries have revamped the educational policies utilizing technical support using remote learning, online learning, and distance education. In fact, the recent pandemic has changed the landscape of teaching and learning in the last two years. Because of the Covid-19 pandemic, the schools and universities have moved from face-to-face to virtual mode of interaction and teaching-learning process. However, the radical change in the teaching and learning process has imposed significant challenges for the instructors and the students in terms of change in the traditional habits and pedagogy, adopting new technologies, student engagement, modification of the curriculum, and restoring the mental health, while maintaining social isolation $[1,2]$. Experts contend that even after the end of Covid-19, online education will be a part of the next generation's education system [3]. The "now normal" age is characterized by a blended mode (online and offline) of learning. It is being adopted by academic institutions and universities. Many organizations are taking advantage of this new way to retrain and re-educate their employees and manage business operations virtually [4]. Moreover, the blended mode of operation has provided an opportunity to reduce operational 
costs in the long run, help prevent the spread of Covid19-like viruses, and truly connect to remote people. As a result, the limited use of video conferencing (VC) platforms has been amplified manifold in quick time. VC platforms Google Meet, Zoom, BlueJeans, Webex, Microsoft Teams, and BigBlueButton have become essential tools for enduring education amidst utter uncertainty and disruption and maintaining business operations and virtual communications using audio, video, and seminars, exploring advanced features like built-in features, such as chat, screen sharing, and recording [5].

Although VC has become an advantageous and comfortable way of communication in recent times, it is not a new invention. Video conferencing was developed to facilitate international communications and increase productivity because it saves travel time and cost as one can meet virtually at any time. However, Covid-19 has changed the face of video communication. In effect, the extant literature has been witnessing a notable expansion. There has been a sizeable number of studies made about VC tools and their usefulness vis-à-vis consumers' behaviors. For instance, Matulin et al. [6] noted that, nowadays, VC is used as a daily application to keep in touch with friends and family, useful for work-from-home culture and distance learning techniques. The availability of a wide variety of tools and techniques has accelerated the usage. The authors carried out a comparative study of various learning tools, such as Zoom, Microsoft Teams, Google Meet, and Skype [6]. Correia et al. [7] mentioned the significance of VC tools in education in the context of Covid-19. VC tools have started gaining importance in the last decade with the advent of massive open online courses (MOOC). In their research, Boyatt et al. [8] pointed out that in the emergence of massive open online courses (MOOC), these tools are available to support the users in teaching-learning activities as the institutions and universities are concerned with e-learning and innovative programs. The online learning experience involves innovation during the transition from face-to-face to online. On the other hand, students can participate in various courses across the world. Archibald et al. [9] observed that candidates prefer video communication as an interviewing technique compared to face-toface (FTF) or telephone. In addition, these VC platforms can be used to collect information relevant to academics and practice. It involves relative ease of use, cost-effectiveness, data management features, and security options. VC mode has certain strengths, such as being easy to use, flexible, convenient, time- and money-saving, and easily accessible. Most of the students are flexible and comfortable while attending the virtual classes. It identifies the levels of satisfaction of the students by online learning in educational institutions. Therefore, it is identified that many students prefer the implementation of online learning programs [10]. Talking about the advantages, Archibald et al. [9] mentioned that the main advantages of the e-learning platform are as follows:

(i) Simplicity and user friendliness: these tools are uncomplicated and easy to use (ii) Accurate recording facility: it allows participants to record the lecture or lesson for future reference

(iii) Time-saving with no travel requirements: doing a meeting using video conference is more time-saving than a face-to-face meeting

Gray et al. [11] argued that using VC platforms, one can use these tools by phones, laptops, and computers. In this context, Parra and Granda [12] reported specific parameters that need to be considered for comparing different VC platforms, such as the attractiveness, efficiency, familiarity, and innovativeness of the product. However, this is not a one-sided story. There are certain drawbacks to using a virtual platform as a teaching method. Many times, it has been observed that students' participation is relatively low in the virtual platform. Also, internet connectivity posits significant challenges, especially in remote rural areas. Many students are not enthusiastic about the virtual classroom $[3,13]$.

For the successful utilization of VC tools and conduction of e-learning, Wang et al. [10] provided a list of requirements, which are as follows:

(i) Students' engagement is highly needed

(ii) The quality of audio and video should be good

(iii) Good communication between students and teachers

Nevertheless, video conferencing (VC) teaching has an overall positive outcome in teaching-learning activity. These learning tools and techniques support the educational activity in this new normal [14-16].

In this paper, we aim to compare a set of popular VC platforms used in India in higher education by instructors and students. Needless to mention that the acceptability of highly technological products, such as VC tools, depends not only on the technical know-how but also on users' experience and usability of the system. User experience is a complex subjective parameter that depends on several conflicting attributes. Therefore, the comparison of $\mathrm{VC}$ tools is an MCDM problem that involves a set of subjective and objective attributes. In this paper, we only consider the opinions of the users. Therefore, our analysis is limited to a multiattribute group decision making (MAGDM) scenario.

The MCDM algorithm enables to compare a set of available options with respect to the selected group of attributes or constraints with varying degrees of preference and objectives. The conflicting nature of the criteria and their interplay posit a challenge in deciding the combined effect on available alternatives for comparison purposes [17]. In other words, the DMs are confronted with imprecise information under uncertainty to arrive at a decision, and often, they land on improper conclusions [18, 19]. To prevent such situations, Zadeh's contribution of introducing the concept of fuzzy sets (FS) has been a major breakthrough since its inception [20]. To further enrich the stated field, Atanassov [21] contributed to the concept of intuitionistic fuzzy sets (IFS) that consider the degree of membership and nonmembership. Although FS and IFS have solved various 
practical problems over several decades, there are some situations wherein the basic assumption that the sum of both memberships equals one gets violated. In this regard, Yager [22] introduced the concept of the Pythagorean fuzzy set (PyFS) and its extended complex generalization, such as the $q$-rung orthopair fuzzy set (qROFS) with the condition $\mu^{q}+$ $9^{q} \leq 1$ [23]. In this context, researchers have also developed and applied an extension of qROFS with $q=3$, which is known as Fermatean fuzzy set (FFS) [18, 24]. However, because of its flexibility and simplicity, PyFS has been widely extended with different aggregation operators and variants of FS, such Dombi operator, probabilistic hesitant fuzzy, intuitionistic fuzzy soft sets, among others, and subsequently, it is applied in solving various real-life issues by many researchers [25-28].

The concept of picture fuzzy sets (PFS) has come into existence for further generalization of IFS to fill the gap in the literature. PFS not only includes the degree of nonmembership but also allows the DM more flexibility and granularity in the analysis of imprecise information by incorporating the degree of neutrality and refusal [29]. Over the years, there have been a substantial number of further extensions of PFS with generalized PF soft set [30], weighted geometric aggregation operators with t-norm and t-conorm [31], interval-valued picture uncertain linguistic set with generalized Hamacher aggregation operators [32], simple to understand and flexible distance-like measures, such as weak interval-valued pseudo-metrics [33] and Dempster-Shafer theory [34], which improved the actual score measures [35], and trapezoidal PFN with Dijkstra algorithm [36] to mention a few. In this context, it is noteworthy to compare PFS with another recently developed and popular variant of classical FS, namely the spherical fuzzy set (SFS) [37]. SFS is essentially a generalization of PFS, and also, it considers the degree of neutral membership [38]. However, in the case of SFS, the square sum of all three memberships is less than or equal to one. In effect, SFS provides more flexibility as compared to PFS in terms of the values of the membership grades. However, PFS provides a relatively lesser complex analysis and considers the refusal aspect as well. Nevertheless, the domain of SFS is a growing field of research that is contributed by several extensions and applications using grey theory, complex aggregation operators, distance measures, and algorithmic modifications of MCDM methods [39-45].

In this work, our analysis stands on users' views on their experiences and usability of the VC platforms. Moreover, VC tools are yet to be extensively used, and all of its features are yet to be known to the majority of the users. Hence, the opinions are associated with a substantial amount of impreciseness that only incorporates positive and negative expressions, however, neutrality and refusal also assume significant considerations. Therefore, for our analysis, we have felt the importance of using PFS in conjunction with MCDM techniques. For comparison purposes, we propose a novel extension of a very recently developed MCDM algorithm known as PROBID [46] in a PF environment. We use another recent algorithm called FUCOM [47] with PFN for deriving the criteria weights. Our initial proposition is that perhaps not all VC platforms are equally preferred by the users when multiple perspectives are considered. The criteria for comparing the $\mathrm{VC}$ platforms are selected on the basis of literature review and the theoretical foundation of usability and UX theory, which is an extension of the technology acceptance model (TAM) [48].

PROBID method offers the following advantages:

(i) It considers all possible ideal solutions and the average solution. Hence, it provides a comprehensive and holistic approach. In essence, this method combines the benefits of the technique for the order of preference by similarity to ideal solution (TOPSIS) and evaluation based on distance from average solution (EDAS) models. According to this model, the most positive ideal solution (PIS) is the one that offers the best possible solution with respect to the influence of the criteria. In the PROBID method, the whole spectrum of PIS, i.e., $1^{\text {st }}, 2^{\text {nd }}, 3^{\text {rd }}$, up to the most negative PIS (i.e., most negative ideal solution or NIS) are calculated with respect to the number of alternatives present in the study, which allows the risk-tolerant decision maker to have wider options. Furthermore, the average solution considers the perspectives of risk averters as well.

(ii) It provides a stable and consistent result, which is free from the rank reversal phenomenon, unlike TOPSIS.

On the other hand, FUCOM provides the following benefits:

(i) A reduced number of pairwise comparisons. FUCOM requires a total of $(n-1)$ number of comparisons, where $n$ is the number of criteria. Therefore, it lowers the possibility of inconsistency in the result because of subjective bias and ambiguity in the judgments.

(ii) It has an inherent feature for determining the consistency by calculating the deviation from consistency (DFC) value, which enables to ensure the validity and robustness of the outcome.

(iii) Stability in the result.

(iv) Ability to work with a large number of criteria set with uncertain and imprecise information.

Because of its fundamental advantages, the FUCOM method has drawn significant interest from researchers and practitioners to solve complex real-life issues. Some of the recent applications of the FUCOM method are the selection of side-loading forklifts [49], supplier selection [50-52], material classification [53], facility location selection $[54,55]$, performance appraisal and compensation management [56], water system management [57], and mineral mapping issues [58]. The fundamental algorithm of FUCOM has witnessed a considerable number of extensions using, for example, the grey theory [59], DombiBonferroni operators with fuzzy numbers [60], Z-numbers [61], fuzzy numbers [62, 63], and fuzzy Bonferroni Mean operator [64]. 
The present paper contributes to extant literature in the following ways:

(i) PROBID is a very recently developed algorithm. We have not found any application of PROBID method so far. The present paper is a first of its kind in applying the PROBID method with a novel extension using PFN to solve a user experience-based real-life issue.

(ii) Though FUCOM has been increasingly used by the researchers, it seems application with $\mathrm{PFN}$ is quite rare in the literature.

(iii) The integrated framework of FUCOM-PROBID is a newly proposed decision support system that shall enable the researchers to solve various complex problems.

(iv) Looking back at the past work, we have observed that the domain of VC has not been explored to a substantial extent. Furthermore, in this paper, a comprehensive MCDM-based approach using PFN is used, which provides a holistic assessment of the $\mathrm{VC}$ tools. Given the context of postpandemic era, the use of $\mathrm{VC}$ is quite promising, and hence, it is quite imperative to compare the VC tools from multiple perspectives. The present study fills the gap in the literature in this respect.

(v) Furthermore, the concept of usability and UX has not been exhaustively used in the literature, and application areas are quite narrow. The present study is an attempt to extend the application domain.

The remainder of this paper is organized as follows: in Section 2, we provide some preliminary concepts of PFN and PFS. Section 3 elaborates the research methodology used in this paper. We present the summary of findings and include necessary discussions including the results of the validation test and sensitivity analysis in Section 4. Section 5 briefly discusses some of the implications of this research and sheds light on some future scope. Finally, Section 6 concludes the paper.

\section{Preliminaries}

In this section, we discuss the definitions and some fundamental properties and operations of PFS and PFN.

2.1. Definition. Let $\widetilde{A}$ denote PFS on a universe of discourse $\mathrm{U}$. Then, $\widetilde{\mathrm{A}}$ is defined as $[65,66]$

$$
\widetilde{A}=x, \mu_{\tilde{A}}(x), \eta_{\tilde{A}}(x), v_{\tilde{A}}(x),
$$

$x \in U ; \mu_{\tilde{A}}(x), \eta_{\widetilde{A}}(x), v_{\widetilde{A}}(x) \in[0,1]$ are the degrees of positive, neutral, and negative membership of $x$ in $\widetilde{A}$, respectively, with the condition that

$$
0 \leq \mu_{A}(x)+\eta_{\mathcal{A}}(x)+v_{\mathcal{A}}(x) \leq 1 \forall x \in U .
$$

The degree of refusal is given by

$$
\pi_{\tilde{A}}^{\sim}(x)=1-\left(\mu_{\tilde{A}}(x)+\eta_{\tilde{A}}(x)+v_{\tilde{A}}(x)\right) \forall x \in U .
$$

For a given element $x$ in $U$, a PFN is represented as

$$
\begin{aligned}
A=\{ & \left\{\left(\mu_{A}, \eta_{A}, v_{A}\right) \mid \mu_{A}, \eta_{A}, v_{A} \in[0,1] \text { and } 0 \leq \mu_{A}\right. \\
& \left.\left.+\eta_{A}+v_{A} \leq 1\right\}\right\} .
\end{aligned}
$$

It is to be noted that PFS is an extended version of the traditional fuzzy sets (FS). For a PFS, if $\eta_{\tilde{A}}(x)=0$, then it becomes an intuitionistic fuzzy set (IFS), while if both $\eta_{\tilde{A}}(x)$ and $v_{\widetilde{A}}(x)=0, \widetilde{\mathrm{A}}$ represents a traditional fuzzy set. With the presence of $\eta_{\mathcal{A}}(x)$, PFS helps in carrying out more granular analysis reflecting on the available imprecise information, and it enhances the accuracy of the result [67]. Furthermore, the degree of refusal provides the opinionmakers the liberty not to express any opinion if they are unaware and/or not interested. It reduces the misinterpretation and error in the result. In summary, PFS deals with impreciseness and uncertainties with greater efficiency.

2.2. Properties. Some of the properties of PFS or PFN are described below $[65,66]$.

Let $\widetilde{A}=x, \mu_{\widetilde{A}}(x), \eta_{\mathcal{A}}(x), v_{\mathcal{A}}(x)$ and $\widetilde{B}=x, \mu_{B}(x)$, $\eta_{\bar{B}}(x), v_{\bar{B}}(x)$ be two PFS $\forall x \in U$; then,

$$
\begin{aligned}
& \widetilde{A} \cup \widetilde{B}=\left\{\left(x, \max \left(\mu_{\widetilde{A}}(x), \mu_{\widetilde{B}}(x)\right), \min \left(\eta_{\widetilde{A}}(x), \eta_{\widetilde{B}}(x)\right), \min \left(v_{\widetilde{A}}(x), v_{\widetilde{B}}(x)\right)\right) \mid x \in U\right\}, \\
& \widetilde{A} \cap \widetilde{B}=\left\{\left(x, \min \left(\mu_{\widetilde{A}}(x), \mu_{\widetilde{B}}(x)\right), \min \left(\eta_{\widetilde{A}}(x), \eta_{\widetilde{B}}(x)\right), \max \left(v_{\widetilde{A}}(x), v_{\widetilde{B}}(x)\right)\right) \mid x \in U\right\}, \\
& \widetilde{A}^{c}=\left\{x, v_{\widetilde{A}}(x), \eta_{\widetilde{A}}(x), \mu_{\widetilde{A}}(x) \mid x \in U\right\}, \\
& \widetilde{A} \subseteq \widetilde{B} \text { if }\left(\mu_{\widetilde{A}}(x) \leq \mu_{\widetilde{B}}(x), \eta_{\widetilde{A}}(x) \leq \eta_{\widetilde{B}}(x), v_{\widetilde{A}}(x) \geq v_{\widetilde{B}}(x) \forall x \in U\right), \\
& \widetilde{A}=\widetilde{B} \text { if } \widetilde{A} \subseteq \widetilde{B} \text { and } \widetilde{B} \subseteq \widetilde{A}, \\
& \widetilde{A} \subseteq \widetilde{B} \text { and } \widetilde{B} \subseteq \widetilde{C} \Rightarrow \widetilde{A} \subseteq \widetilde{C}, \\
&\left(\widetilde{A}^{c}\right)^{c}=\widetilde{A} .
\end{aligned}
$$


2.3. Operations $[65,66]$. Let $A=\left(\mu_{A}, \eta_{A}, v_{A}\right)$ and $B=\left(\mu_{B}, \eta_{B}, v_{B}\right)$ be any two PFNs. The following are some of the basic operations:

$$
\begin{aligned}
A \oplus B & =\left(\mu_{A}+\mu_{B}-\mu_{A} \mu_{B}, \eta_{A} \eta_{B}, v_{A} v_{B}\right), \\
A \otimes B & =\left(\mu_{A} \mu_{B}, \eta_{A}+\eta_{B}-\eta_{A} \eta_{B}, v_{A}+v_{B}-v_{A} v_{B}\right), \\
\lambda A & =\left(1-\left(1-\mu_{A}\right)^{\lambda}, \eta_{A}^{\lambda}, v_{A}^{\lambda}\right) ; \lambda>0, \\
A^{\lambda} & =\left(\mu_{A}^{\lambda}, 1-\left(1-\eta_{A}\right)^{\lambda}, 1-\left(1-v_{A}\right)^{\lambda} ; \lambda>0,\right. \\
A \oplus B & =B \oplus A, \\
A \otimes B & =B \otimes A, \\
\left(A^{\lambda 1}\right)^{\lambda 2} & =A^{\lambda 1 \lambda 2}, \\
(A \otimes B)^{\lambda} & =A^{\lambda} \otimes B^{\lambda} .
\end{aligned}
$$

2.4. Defuzzification $[68,69]$. The two-stage defuzzification of a PFN is described below.

Step 1. Defining new positive and negative memberships:

$$
\begin{aligned}
& \dot{\mu}_{A}=\mu_{A}+\frac{\eta_{A}}{2}, \\
& \dot{v}_{A}=v_{A}+\frac{\eta_{A}}{2} .
\end{aligned}
$$

Step 2. Calculation of the defuzzification value:

$$
\gamma_{A}=\mu_{A}^{\prime}+\pi_{A}\left(\frac{1+\mu_{A}^{\prime}-v_{A}^{\prime}}{2}\right) \text {. }
$$

2.5. Distance Measures [70, 71]. Let $\widetilde{A}=x, \mu_{A}(x)$, $\eta_{\widetilde{A}}(x), v_{\widetilde{A}}(x)$ and $\widetilde{B}=x, \mu_{\tilde{B}}(x), \eta_{\widetilde{B}}(x), v_{\widetilde{B}}(x)$ be two PFS $\forall x \in U$, where $x=\left\{x_{1}, x_{2}, x_{3}, \ldots, x_{n}\right\}$.

Normalized Hamming distance:

$$
\begin{aligned}
d^{H}(\widetilde{A}, \widetilde{B})= & \frac{1}{n} \sum_{i=1}^{n}\left(\left|\mu_{\widetilde{A}}\left(x_{i}\right)-\mu_{\widetilde{B}}\left(x_{i}\right)\right|+\left|\eta_{\widetilde{A}}\left(x_{i}\right)-\eta_{\widetilde{B}}\left(x_{i}\right)\right|\right. \\
& \left.+\left|v_{\widetilde{A}}\left(x_{i}\right)-v_{\widetilde{B}}\left(x_{i}\right)\right|\right) .
\end{aligned}
$$

Normalized Euclidean distance:

$$
d^{E}(\tilde{A}, \widetilde{B})=\sqrt{\frac{1}{n} \sum_{i=1}^{n}\left(\left(\mu_{\tilde{A}}\left(x_{i}\right)-\mu_{\widetilde{B}}\left(x_{i}\right)\right)^{2}+\left(\eta_{\widetilde{A}}\left(x_{i}\right)-\eta_{\widetilde{B}}\left(x_{i}\right)\right)^{2}+\left(v_{\widetilde{A}}\left(x_{i}\right)-v_{\widetilde{B}}\left(x_{i}\right)\right)^{2}\right)}
$$

2.6. Score and Accuracy Functions [66]. The score function of any PFN $\mathrm{A}$ is given as

$$
S_{A}=\mu_{A}-v_{A} .
$$

The accuracy function is defined as:

$$
H_{A}=\mu_{A}+\eta_{A}+v_{A} \text {. }
$$

In this regard, the rules for comparing any two PFNs, such as $\mathrm{A}$ and $\mathrm{B}$ are given as follows:
(i) If $S_{A} \prec S_{B}$, then $A \prec B$
(ii) If $S_{A}>S_{B}$, then $A>B$
(iii) If $S_{A}=S_{B}, H_{A} \prec H_{B}$, then $A \prec B$
(iv) If $S_{A}=S_{B}, H_{A}>H_{B}$, then $A>B$
(v) If $S_{A}=S_{B}, H_{A}=H_{B}$, then $A=B$

2.7. Absolute and Actual Score. The necessity of calculating the absolute and actual scores stems from the need to consider all three degrees of membership functions as one of the distinct features of PFS is neutrality [72]. Accordingly, the steps are described below.
Step 3. Identification of the positive ideal solution (PIS) For a set of $n$ number of PFNs, PIS is given as

$$
\begin{array}{r}
Z^{+}=\left(\mu^{+}, \eta^{+}, v^{+}\right)=\left(\max _{i} \mu_{i}, \min _{i} \eta_{i}, \min _{i} v_{i}\right), \\
\text { where } i=1,2, \ldots, n .
\end{array}
$$

Step 4. Find out goal differences for each PFN Positive goal difference:

$$
\mu_{i+}=\mu^{+}-\mu_{i}
$$

Negative goal difference:

$$
v_{i-}=v_{i}-v^{+} .
$$

Step 5. Find out the average neutral degree:

$$
\bar{\eta}=\frac{1}{n} \sum_{i=1}^{n} \eta_{i}
$$

Step 6. Calculation of the absolute score for each PFN: 


$$
S_{i(a b s)}=\left(1-\mu_{i+}\right)-v_{i-} .
$$

Step 7. Derive the actual score for each PFN:

$$
S_{i(a c t)}=\frac{S_{i(a b s)}}{1-\left(\bar{\eta}-\eta_{i}\right)} .
$$

Here, the rules applicable are as follows:

$$
\begin{aligned}
& \text { (i) If } S_{A(a c t)}>S_{B(a c t)} \text {, then } A>B \\
& \text { (ii) If } S_{A(a c t)}=S_{B(a c t)} \text {, then if } \mu_{A}>\mu_{B} \text { and } \eta_{A} \geq \\
& \eta_{B} \text { then } A>B \\
& \text { (iii) If } S_{A(a c t)}=S_{B(a c t)} \text { and } \mu_{A} \geq \mu_{B} \text { and } \eta_{A}<\eta_{B} \text {, then if } \\
& v_{A} \leq v_{B} \text { then } A>B \text {, otherwise } A \prec B
\end{aligned}
$$

\section{Materials and Methods}

In this paper, we use a new decision support framework based on the extension of the PROBID method using PFNs, wherein the criteria weights are determined by applying the FUCOM algorithm with the actual score values of PFNs. The procedural steps followed to address the problem of comparing some of the popular VC platforms in India using our proposed methodology are presented pictorially in Figure 1. In this section, a detailed description of the research methodology is provided.

3.1. Criteria Selection. In this paper, we use the theoretical foundation of usability and user experience (UX) to understand the usefulness of some of the popular VC platforms to the users, more specifically, to the educators and students. In the post-Covid-19 phase, as the online medium has gained substantial importance in teaching-learning in higher education, the availability and stability have become two dominant features of quality service [73, 74]. According to ISO 9241-210, 2010 [75], the concept of UX entails the perception and responses of the users while using a given service or system. The ability of a service provider in achieving user satisfaction in a given use context determines the effectiveness and efficiency, and thereby, it enhances usability. In essence, the usability, affect, and user value are the subsets of the UX set $[76,77]$. There are other perspectives on usability and UX as well, for instance, simplicity in use for providing a happy experience [78], fitness, suitability of use in terms of aesthetics, pleasure, and attractiveness [79], and flexibility of the service providers [1] among others. A number of studies are done using the UX concept, mostly in the domain of computer networking, transmission, mobile communication, and system design, using virtual reality [for example, [76-81]]. In line with the understanding of usability and UX theory and observations made in the extant literature, we select the list of criteria (see Table 1) for comparing a set of popular VC platforms (see Table 2) used in higher education in India.
3.2. Formation of the Group of DMs. The profile of the respondents is provided in Table 3. In our study, a group of 14 regular users have participated. The sample size meets the requirement in group decision-making [82-84]. A Google form-based online survey is administered.

3.3. FUCOM Method. The procedural steps of the FUCOM algorithm [47] are given in the following.

Step 8. Ordering of the criteria based on their relative priorities as defined by the DMs.

Suppose $C=\left\{C_{1}, C_{2}, C_{3}, \ldots, C_{n}\right\}$ represents the set of criteria. Let the order of the criteria based on the preference of the DMs be $C_{j}(1)>C_{j}(2)>C_{j}(3)>\cdots C_{j}(r)$, where $r$ is the rank of the particular criterion. However, there may be the situations where any two criteria may hold the same preferential rank (in that case, an " =" may be used).

Step 9. Calculation of the comparative priority of the criteria.

The comparative priority $(\mathrm{CP})$ of the criterion $\mathrm{C}_{\mathrm{j}}(\mathrm{r})$ as compared with $C_{j}(r+1)$ is given by $\Phi_{r /(r+1)}$.

The CP can be defined (a) according to DM's preference or (b) using a predetermined scale, wherein the criterion with $r=1$ (i.e., ranked first) is the most preferred one. The other criteria are compared with the most preferred criterion. It is already mentioned that the FUCOM method requires a total of (n-1) number of pairwise comparisons.

Step 10. Calculation of the final weights of the criteria.

The final weights are derived subject to the following two conditions:

a)

$$
\frac{w_{r}}{w_{r+1}}=\Phi_{r /(r+1)}
$$

b) Mathematical transitivity:

$$
\frac{w_{r}}{w_{r+2}}=\Phi_{r /(r+1)} \otimes \Phi_{(r+1) /(r+2)} .
$$

The full consistency or maximum possible consistency is obtained if $\operatorname{DFC}(\chi)$ is minimum subject to the fulfilment of the conditions (refer the expressions (34) and (35)). The final model is constructed as

$$
\begin{aligned}
& \operatorname{Min} \chi, \\
& \text { s.t. } \\
& \left|\frac{w_{j(r)}}{w_{j(r+1)}}-\Phi_{r /(r+1)}\right| \leq \chi, \quad \forall j, \\
& \left|\frac{w_{j(r)}}{w_{j(r+2)}}-\Phi_{r /(r+1)} \otimes \Phi_{((r+1)) /(r+2)}\right| \leq \chi, \quad \forall j, \\
& \sum w_{j}=1, w_{j} \geq 0, \quad \forall j .
\end{aligned}
$$




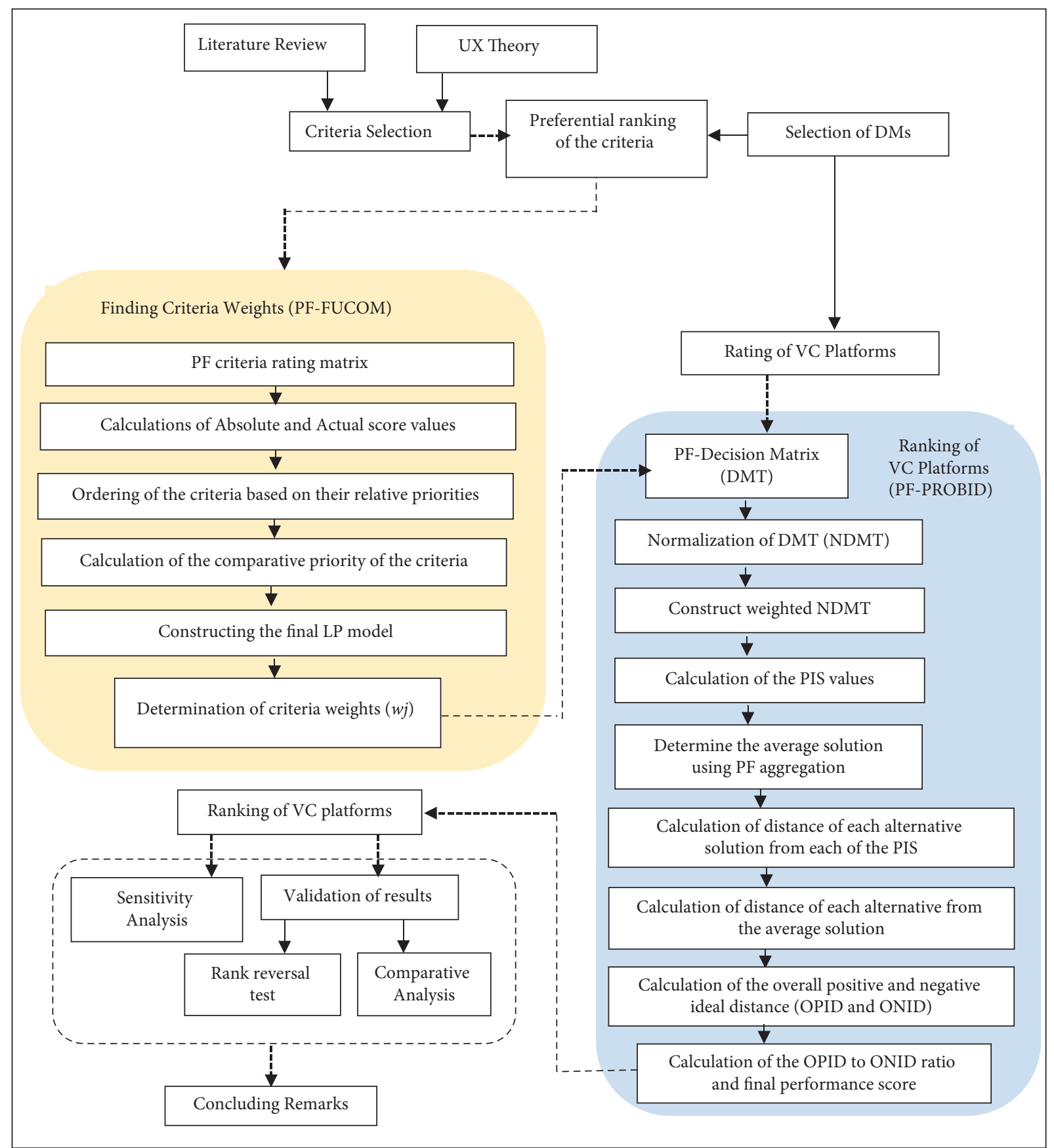

FiguRE 1: Flow of steps of the research framework.

TABLE 1: List of criteria considered to compare VC platforms.

\begin{tabular}{lccc}
\hline S/L & Criteria & Description & Effect direction \\
\hline C1 & User friendliness & Minimal action, easy access & Max \\
C2 & Compatibility & Operations from multiple types of devices, applications through web, multipurpose use & Max \\
C3 & Quality of transmission & Voice and video quality & Max \\
C4 & Features & File transfer, recording, break-rooms, playback, screen sharing, remote control, etc. & Max \\
C5 & Bandwidth consumption & Requirement for Internet speed & Min \\
C6 & Awareness & Degree of popularity/familiarity, number of users & Max \\
C7 & Security and privacy & Security of data, private credentials, etc. & Max \\
C8 & Cost & Subscription, cost for large scale operations & Min \\
\hline
\end{tabular}

Note: the criteria are identified using the premise of the UX theory and in tune with past work. Descriptions are summarized as per the understanding of the authors and with reference to extant literature. 
TABLE 2: List of VC platforms under comparison.

\begin{tabular}{lc}
\hline S/L & VC platform \\
\hline A1 & Zoom \\
A2 & Microsoft Teams \\
A3 & Google Meet \\
A4 & Webex \\
A5 & GotoMeeting \\
A6 & We Chat \\
A7 & WhatsApp \\
A8 & Skype \\
\hline
\end{tabular}

TABLE 3: Respondents' profile.

\begin{tabular}{lcccc}
\hline Decision maker & Gender & Total professional experience (in years) & Role & No. of years in using VC platforms \\
\hline DM1 & Male & $6-10$ years & Instructor/educators & $2-5$ years \\
DM2 & Female & $6-10$ years & Instructor/educators & More than 5 years \\
DM3 & Male & More than 20 years & PG student & $2-5$ years \\
DM4 & Male & $10-15$ years & Instructor/educators & $1-2$ years \\
DM5 & Male & $0-5$ years & PG student & $2-5$ years \\
DM6 & Male & $10-15$ years & Instructor/educators & More than 5 years \\
DM7 & Male & $0-5$ years & PG student & $1-2$ years \\
DM8 & Male & $0-5$ years & PG student & $1-2$ years \\
DM9 & Male & $5-10$ years & Instructor/educators & More than 5 years \\
DM10 & Male & $16-20$ years & Instructor/educators & More than 5 years \\
DM11 & Female & $0-5$ years & PG student & $1-2$ years \\
DM12 & Female & $0-5$ years & PG student & $2-5$ years \\
DM13 & Male & $5-10$ years & Instructor/educators & $2-5$ years \\
DM14 & Male & More than 20 years & Instructor/educators & More than 5 years \\
\hline
\end{tabular}

By solving the final model as described above, we obtain the weights of the criteria $\left(w_{j}\right)$.

3.4. PROBID Method. The PROBID algorithm works on a combined essence of TOPSIS and EDAS methods. The steps to compute the results using the classic PROBID method [46] are described in the following.

Step 11. Normalization of DMT.

Using the vector normalization scheme, DMT $X=\left[x_{i j}\right]_{m \times n}$ can be converted into a normalized DMT (NDMT) $N=\left[n_{i j}\right]_{m \times n}$, where the elements are given by

$$
n_{i j}=\frac{x_{i j}}{\sqrt{\sum_{i=1}^{m} x_{i j}^{2}}}
$$

Step 12. Formation of the weighted NDMT.

The weighted NDMT (WNDMT) is represented by $V=\left[v_{i j}\right]_{m \times n}$, where the elements are derived as

$$
\begin{aligned}
v_{i j}= & n_{i j} \times w_{j}, \\
i \in & \{1,2,3, \ldots, m\} ; j \in\{1,2,3, \ldots, n\} \\
& w_{j} \text { is the weight of } j^{t h} \text { criterion. }
\end{aligned}
$$

Step 13. Calculation of the PIS values.
Let $P_{k(j)} ; k=1,2, \ldots, m$ be the PIS values, where $P_{1(j)}$ is the most favorable PIS value. Therefore, $P_{m(j)}$ is the most nonfavorable PIS, i.e., most NIS value. The $\mathrm{k}^{\mathrm{th}}$ PIS value is given by

$$
P_{k(j)}=\left\{\left(\max \left(v_{j}, k\right) ; j \in j^{+}\right),\left(\min \left(v_{j}, k\right) ;\right) ; j \in j^{-}\right\},
$$

$j^{+}$is the set of maximizing criteria and $j^{-}$is the set of minimizing criteria from the criteria set for $j \in\{1,2,3, \ldots, n\}$.

Step 14. Determine the average solution.

The average solution $v_{\operatorname{avg}(j)}$ is given by

$$
v_{\text {avg }(j)}=\frac{\sum_{k=1}^{m} P_{k(j)}}{m} \text { for } j \in\{1,2,3, \ldots, n\} .
$$

Step 15. Calculation of the distance of each alternative solution from each of the $m$ number of PIS.

Applying the standard formula of Euclidean distance of the $i^{t h}$ alternative from each of the PIS is derived as

$$
\begin{gathered}
d_{i(k)}=\sqrt{\sum_{j=1}^{n}\left(v_{i j}-P_{k(j)}\right)^{2}} ; i \in\{1,2, \ldots m\} ; \\
k \in\{1,2,3, \ldots, m\} .
\end{gathered}
$$

Step 16. Calculation of distance of each alternative from the average solution. 
In the same way, the Euclidean distances are calculated as

$$
d_{i(\text { avg })}=\sqrt{\sum_{j=1}^{n}\left(v_{i j}-v_{\operatorname{avg}(j)}\right)^{2}} ; \quad i \in\{1,2, \ldots, m\} .
$$

Step 17. Calculation of the overall positive ideal distance (OPID).

The OPID is essentially the weighted sum distance of an alternative from the first half of the PIS values and is expressed as

$$
d_{i(\text { pos-ideal })}=\left\{\begin{array}{l}
\sum_{k=1}^{(m+1) / 2} \frac{d_{i(k)}}{k}, \quad i \in\{1,2, \ldots m\} ; m \text { is odd } ; k=1,2,3, \ldots, \\
\sum_{k=1}^{m / 2} \frac{d_{i(k)}}{k}, \quad i \in\{1,2, \ldots m\} ; m \text { is even } ; k=1,2,3, \ldots
\end{array}\right.
$$

Step 18. Calculation of the overall negative ideal distance (ONID).
The ONID is essentially the weighted sum distance of an alternative from the second half of the PIS values and is expressed as

$$
d_{i \text { (neg-ideal })} \begin{cases}\sum_{k=(m+1) / 2}^{m} \frac{d_{i(k)}}{m-k+1}, & i \in\{1,2, \ldots, m\} ; m \text { is odd } ; k=1,2,3 \ldots, \\ \sum_{k=(m / 2)+1}^{m} \frac{d_{i(k)}}{m-k+1}, & i \in\{1,2, \ldots, m\} ; m \text { is even; } k=1,2,3, \ldots\end{cases}
$$

Unlike OPID, in case of ONID, the weight increases as $k$ approaches $m$.

Step 19. Calculation to OPID to ONID ratio.

The ratio of OPID to ONID is given by

$$
R_{i}=\frac{d_{i(\text { pos-ideal })}}{d_{i(\text { neg-ideal })}}
$$

Step 20. Determine the final performance score.

The final performance score $P S_{i}$ is given by

$$
P S_{i}=\frac{1}{1+R_{i}^{2}}+d_{i(\text { avg })} ; \quad i \in\{1,2, \ldots, m\} .
$$

It may be noted that if $R_{i} \longrightarrow 0, P S_{i}$ increases, which means the respective alternative solution becomes closer to most PIS. Hence, the higher the value of $P S_{i}$, the more preferable the corresponding alternative.

3.5. The Proposed PF-FUCOM-PROBID Methodology. In this subsection, we shall elaborate the steps of our proposed methodology. In our study, we have the following:

$C_{j}$, where $j=1,2, \ldots, n(n$ is finite and $\geq 2)$ : the number of criteria or attributes
$A_{i}$, where $i=1,2, \ldots, m$ ( $m$ is finite and $\geq 2$ ): the number of alternatives or VC platforms

$E_{t}$, where $t=1,2, \ldots, p(p$ is finite and $\geq 2)$ : the number of DMs participated

Step 21. Formation of the linguistic response matrix for criteria rating.

Let $\partial_{j}^{t}$ be the relative importance of the $j^{\text {th }}$ criterion as opined by $t^{t h} \mathrm{DM}$, where $\partial_{j}^{t}$ may be positive, negative, neutral, and no response or refusal. In this paper, for criteria rating, refusal is not considered. Hence, for rating, there are three options: $\mathrm{H}$ (if the corresponding criterion is highly significant; positive membership), $L$ (if the corresponding criterion is less significant; negative membership), and $\mathrm{N}$ (if the significance is indeterminate, i.e., not possible to say significant or nonsignificant; neutral membership). The linguistic response matrix for $t^{t h} \mathrm{DM}$ is formed as

$$
\partial^{t}=\left(\begin{array}{c}
\partial_{1}^{t} \\
\partial_{2}^{t} \\
\cdot . \\
\cdot . \\
\partial_{j}^{t}
\end{array}\right)_{n \times 1}
$$


Table 4 provides the rating of the DMs with respect to different criteria.

Step 22. Construction of the PF rating matrix for the criteria.

After aggregating the responses of all DMs considering the proportion of type of responses (positive, neutral, and negative) [85], we get the $\mathrm{PF}$ rating matrix, which is expressed as

$$
\tilde{\partial}=\left(\begin{array}{c}
\tilde{\partial}_{1} \\
\tilde{\partial}_{2} \\
\cdots \\
\tilde{\partial}_{n}
\end{array}\right)_{n \times 1} .
$$

It may be noted that $\tilde{\partial}_{j}(j=1,2, \ldots, n)$ is also a PFN.

Step 23. Calculation of the actual score values for the criteria.

Using the PF rating matrix, the actual score values are calculated using the expressions from (15) to (20).

Step 24. Priority-based ordering of the criteria.

The relative priority order is decided on the basis of the calculated actual scores of the criteria.

Step 25. Defining the comparative priority (CP) of the criteria.

Firstly, the most significant criterion having the highest actual score value is identified. Then, all other criteria are compared with the same for getting the proportional CP values.

Step 26. Formation of the final linear programming (LP) model.

Using conditions (21) and (25), the final LP model is formulated in the form of expression (26).

Step 27. Determining the criteria weights.

We determine the weights of the criteria by solving the final LP model using the Lingo (version 19) software.

Step 28. Formation of the linguistic response matrix for the rating of the alternatives.

Suppose $\ell_{i j}^{t}$ is the relative significance of $A_{i}$ with respect to $C_{j}$ (on linguistic scale) as given by $t^{\text {th }} \mathrm{DM}$. In this study, $\ell_{\mathrm{ij}}^{\mathrm{t}}$ may be $\mathrm{H}$ or $G$ (if the corresponding criterion is highly significant or good; positive membership), $L$ or B (if the corresponding criterion is less significant or bad; negative membership), and $\mathrm{N}$ (if the significance is indeterminate, i.e., not possible to say significant or nonsignificant; neutral membership). The linguistic response matrix for the rating of the alternatives is given by

$$
\ell^{t}=\left(\begin{array}{ccc}
\ell_{11}^{t} & \cdots & \ell_{1 j}^{t} \\
\vdots & \ddots & \vdots \\
\ell_{i 1}^{t} & \cdots & \ell_{i j}^{t}
\end{array}\right)_{m \times n} .
$$

Table 5 provides the linguistic response matrix.
TABLE 4: Rating of the criteria using linguistic scale.

\begin{tabular}{lcccccccc}
\hline \multirow{2}{*}{ Decision maker } & \multicolumn{7}{c}{ Rating of the criteria } \\
& C1 & C2 & C3 & C4 & C5 & C6 & C7 & C8 \\
\hline DM1 & H & N & N & H & L & L & H & L \\
DM2 & H & H & N & N & H & H & H & N \\
DM3 & N & H & L & L & L & L & N & L \\
DM4 & H & N & H & H & N & N & H & N \\
DM5 & H & H & H & L & L & H & N & H \\
DM6 & H & H & H & H & H & N & H & H \\
DM7 & H & H & H & H & N & N & L & N \\
DM8 & H & H & H & N & N & L & N & N \\
DM9 & H & H & H & H & N & L & H & H \\
DM10 & H & L & N & H & H & L & N & H \\
DM11 & H & H & H & H & H & N & H & N \\
DM12 & N & H & H & N & N & H & N & N \\
DM13 & H & H & H & N & N & L & N & H \\
DM14 & L & H & H & H & H & N & H & N \\
\hline
\end{tabular}

Note: the colors are representing the nature of the criteria. Green: maximizing criteria, and red: minimizing criteria.

Step 29. Deriving the PF decision matrix (PF-DMT). The PF decision matrix is given as

$$
\widetilde{X}=\left(\begin{array}{ccc}
\tilde{x}_{11} & \cdots & \tilde{x}_{1 j} \\
\vdots & \ddots & \vdots \\
\tilde{x}_{i 1} & \cdots & \tilde{x}_{i j}
\end{array}\right)_{m \times n}
$$

Here, $\tilde{x}_{i j}=\mu_{i j}, \eta_{i j}, v_{i j}$ is the PFN that indicates the rating of $A_{i}$ with respect to $C_{j}$ after aggregating the linguistic responses of individual DMs and calculation of the proportion of the type of responses (positive, neutral, and negative).

Step 30. Normalization of the elements of PF-DMT.

The normalized PF decision matrix (NPF-DMT) $\tilde{N}$ is represented by its elements as given in the following:

$$
\widetilde{N}=\left[\widetilde{\aleph_{i j}}\right]_{m \times n}
$$

Here,

$$
\begin{aligned}
\widetilde{\aleph_{i j}}=\widetilde{x_{i j}}\left(\text { for maximizing criteria) and }{\widetilde{x_{i j}}}^{c}\right. \\
\cdot(\text { for minimizing criteria }) .
\end{aligned}
$$

The value for $\tilde{\mathrm{x}}_{\mathrm{ij}}{ }^{c}$ is derived using the expression (6). It may be noted that $\widetilde{\aleph_{i j}}, \widetilde{x_{i j}}$, and $\widetilde{\mathrm{x}}_{\mathrm{ij}}{ }^{\mathrm{c}}$ are PFNs.

Step 31. Construct the weighted normalized decision matrix $\widehat{\mathrm{NW}}$.

The elements of $\overparen{\mathrm{NW}}$ are given as

$$
\widetilde{n w_{i j}}=w_{j} \widetilde{\aleph_{i j}} \text {. }
$$

Here, $w_{j}$ is derived in Step 27 , and $\widetilde{\aleph}_{i j}$ is obtained at Step 30. It may be noted that $\widetilde{n w_{i j}}$ is also a PFN.

Step 32. Calculation of the PIS values.

As described in the Step 23, (Section 3.4), using the expressions (28) and (39) in this step, we calculate the PIS values $P_{k(j)}$, which are also PFNs.

Step 33. Find the average solution. 
TABLE 5: Linguistic response matrix for rating the alternatives.

\begin{tabular}{|c|c|c|c|c|c|c|c|c|c|c|c|c|c|c|c|c|}
\hline \multirow{2}{*}{ Decision maker } & \multicolumn{8}{|c|}{$\mathrm{C} 1$} & \multicolumn{8}{|c|}{$\mathrm{C} 2$} \\
\hline & A1 & $\mathrm{A} 2$ & A3 & A4 & A5 & A6 & A7 & A8 & A1 & $\mathrm{A} 2$ & A3 & A4 & A5 & A6 & A7 & A8 \\
\hline DM1 & G & $\mathrm{N}$ & G & $\mathrm{B}$ & $\mathrm{N}$ & G & G & $\mathrm{B}$ & G & $\mathrm{N}$ & G & $\mathrm{N}$ & $\mathrm{N}$ & $\mathrm{B}$ & $\mathrm{B}$ & $\mathrm{B}$ \\
\hline DM2 & $\mathrm{N}$ & $\mathrm{N}$ & G & $\mathrm{N}$ & $\mathrm{N}$ & $\mathrm{N}$ & G & $\mathrm{N}$ & G & $\mathrm{N}$ & $\mathrm{N}$ & $\mathrm{N}$ & $\mathrm{N}$ & $\mathrm{N}$ & G & G \\
\hline DM3 & $\mathrm{N}$ & $\mathrm{N}$ & G & $\mathrm{B}$ & $\mathrm{N}$ & $\mathrm{B}$ & $\mathrm{N}$ & $\mathrm{N}$ & G & G & $\mathrm{N}$ & G & $\mathrm{N}$ & B & $\mathrm{B}$ & $\mathrm{N}$ \\
\hline DM4 & G & G & G & $\mathrm{B}$ & B & $\mathrm{N}$ & G & B & G & G & G & G & G & $\mathrm{N}$ & $\mathrm{N}$ & G \\
\hline DM5 & $\mathrm{N}$ & G & G & $\mathrm{B}$ & B & $\mathrm{N}$ & $\mathrm{N}$ & $\mathrm{N}$ & G & $\mathrm{N}$ & B & $\mathrm{B}$ & $\mathrm{B}$ & B & G & $\mathrm{N}$ \\
\hline DM6 & G & G & G & $\mathrm{N}$ & $\mathrm{N}$ & $\mathrm{N}$ & G & $\mathrm{N}$ & G & $\mathrm{N}$ & G & G & $\mathrm{N}$ & $\mathrm{N}$ & B & $\mathrm{N}$ \\
\hline DM7 & B & G & B & $\mathrm{N}$ & $\mathrm{N}$ & $\mathrm{N}$ & G & G & B & G & G & $\mathrm{N}$ & $\mathrm{N}$ & $\mathrm{N}$ & G & G \\
\hline DM8 & G & $\mathrm{N}$ & G & $\mathrm{N}$ & $\mathrm{N}$ & $\mathrm{N}$ & G & $\mathrm{N}$ & $\mathrm{N}$ & B & G & G & $\mathrm{N}$ & $\mathrm{N}$ & G & G \\
\hline DM9 & G & G & $\mathrm{N}$ & $\mathrm{N}$ & $\mathrm{N}$ & B & B & $\mathrm{N}$ & G & G & G & $\mathrm{N}$ & B & B & B & B \\
\hline DM10 & G & $\mathrm{N}$ & $\mathrm{N}$ & B & $\mathrm{N}$ & $\mathrm{N}$ & G & $\mathrm{N}$ & G & $\mathrm{N}$ & G & B & B & $\mathrm{N}$ & G & G \\
\hline DM11 & G & B & G & B & B & B & $\mathrm{N}$ & B & G & G & B & $\mathrm{N}$ & $\mathrm{N}$ & B & $\mathrm{N}$ & B \\
\hline DM12 & $\mathrm{N}$ & G & G & $\mathrm{N}$ & $\mathrm{N}$ & $\mathrm{N}$ & G & B & $\mathrm{N}$ & G & G & $\mathrm{N}$ & $\mathrm{N}$ & G & G & $\mathrm{N}$ \\
\hline DM13 & G & $\mathrm{N}$ & G & G & $\mathrm{N}$ & B & G & B & G & G & G & G & $\mathrm{N}$ & $\mathrm{N}$ & $\mathrm{N}$ & $\mathrm{N}$ \\
\hline DM14 & G & G & G & G & G & $\mathrm{N}$ & G & $\mathrm{N}$ & G & G & G & $\mathrm{N}$ & $\mathrm{N}$ & $\mathrm{N}$ & G & $\mathrm{N}$ \\
\hline \multirow{2}{*}{ Decision maker } & \multicolumn{8}{|c|}{ C3 } & \multicolumn{8}{|c|}{ C4 } \\
\hline & A1 & A2 & A3 & $\mathrm{A} 4$ & A5 & A6 & A7 & A8 & A1 & A2 & A3 & $\mathrm{A} 4$ & A5 & A6 & A7 & A8 \\
\hline DM1 & $\mathrm{N}$ & $\mathrm{G}$ & $\mathrm{G}$ & G & $\mathrm{N}$ & $\mathrm{N}$ & B & $\mathrm{N}$ & $\mathrm{G}$ & $\mathrm{N}$ & $\mathrm{N}$ & $\mathrm{G}$ & $\mathrm{N}$ & B & B & $\mathrm{N}$ \\
\hline DM2 & $\mathrm{N}$ & $\mathrm{N}$ & G & G & $\mathrm{N}$ & $\mathrm{N}$ & G & $\mathrm{N}$ & G & $\mathrm{N}$ & G & $\mathrm{N}$ & $\mathrm{N}$ & $\mathrm{N}$ & G & G \\
\hline DM3 & $\mathrm{N}$ & G & G & $\mathrm{N}$ & B & B & B & $\mathrm{N}$ & $\mathrm{N}$ & G & $\mathrm{N}$ & G & $\mathrm{N}$ & B & B & $\mathrm{N}$ \\
\hline DM4 & B & $\mathrm{G}$ & $\mathrm{G}$ & $\mathrm{N}$ & $\mathrm{N}$ & $\mathrm{N}$ & G & G & $\mathrm{N}$ & G & G & B & B & $\mathrm{N}$ & B & $\mathrm{N}$ \\
\hline DM5 & G & G & G & G & $\mathrm{N}$ & $\mathrm{N}$ & $\mathrm{N}$ & B & B & G & G & $\mathrm{N}$ & B & $\mathrm{N}$ & G & $\mathrm{N}$ \\
\hline DM6 & $\mathrm{N}$ & $\mathrm{N}$ & G & G & $\mathrm{N}$ & $\mathrm{N}$ & $\mathrm{N}$ & G & G & G & G & G & B & $\mathrm{N}$ & $\mathrm{N}$ & B \\
\hline DM7 & $\mathrm{N}$ & B & B & B & B & B & $\mathrm{N}$ & G & $\mathrm{N}$ & G & G & $\mathrm{N}$ & G & $\mathrm{N}$ & $\mathrm{N}$ & $\mathrm{N}$ \\
\hline DM8 & G & G & G & G & $\mathrm{N}$ & $\mathrm{N}$ & $\mathrm{N}$ & G & G & G & $\mathrm{N}$ & G & $\mathrm{N}$ & B & B & $\mathrm{N}$ \\
\hline DM9 & G & G & G & $\mathrm{N}$ & B & G & B & $\mathrm{N}$ & G & B & B & B & B & B & B & $\mathrm{N}$ \\
\hline DM10 & G & $\mathrm{N}$ & $\mathrm{N}$ & B & $\mathrm{N}$ & B & G & $\mathrm{N}$ & B & G & $\mathrm{N}$ & $\mathrm{N}$ & B & B & $\mathrm{N}$ & G \\
\hline DM11 & G & G & $\mathrm{N}$ & B & G & B & B & G & G & G & G & $\mathrm{N}$ & $\mathrm{N}$ & $\mathrm{N}$ & G & $\mathrm{N}$ \\
\hline DM12 & G & G & G & $\mathrm{N}$ & $\mathrm{N}$ & $\mathrm{N}$ & G & $\mathrm{N}$ & G & G & G & $\mathrm{N}$ & $\mathrm{N}$ & G & $\mathrm{N}$ & G \\
\hline DM13 & G & $\mathrm{N}$ & $\mathrm{N}$ & G & $\mathrm{N}$ & $\mathrm{N}$ & $\mathrm{N}$ & B & G & $\mathrm{N}$ & G & $\mathrm{N}$ & $\mathrm{N}$ & $\mathrm{N}$ & $\mathrm{N}$ & B \\
\hline DM14 & G & G & G & G & B & $\mathrm{N}$ & G & B & B & $\mathrm{N}$ & B & $\mathrm{G}$ & G & $\mathrm{N}$ & $\mathrm{N}$ & $\mathrm{N}$ \\
\hline \multirow{2}{*}{ Decision maker } & \multicolumn{8}{|c|}{ C5 } & \multicolumn{8}{|c|}{ C6 } \\
\hline & A1 & A2 & A3 & A4 & A5 & A6 & A7 & A 8 & A1 & A2 & A3 & $\mathrm{A} 4$ & A5 & A6 & A7 & A8 \\
\hline DM1 & $\mathrm{L}$ & $\mathrm{H}$ & $\mathrm{L}$ & $\mathrm{H}$ & $\mathrm{N}$ & $\mathrm{N}$ & $\mathrm{N}$ & $\mathrm{N}$ & $\mathrm{H}$ & $\mathrm{H}$ & $\mathrm{H}$ & $\mathrm{H}$ & $\mathrm{N}$ & $\mathrm{H}$ & $\mathrm{H}$ & $\mathrm{H}$ \\
\hline DM2 & $\mathrm{H}$ & $\mathrm{N}$ & $\mathrm{H}$ & $\mathrm{N}$ & $\mathrm{N}$ & $\mathrm{N}$ & $\mathrm{H}$ & $\mathrm{N}$ & $\mathrm{N}$ & $\mathrm{N}$ & $\mathrm{H}$ & $\mathrm{N}$ & $\mathrm{N}$ & $\mathrm{N}$ & $\mathrm{H}$ & $\mathrm{H}$ \\
\hline DM3 & $\mathrm{L}$ & $\mathrm{N}$ & $\mathrm{H}$ & $\mathrm{H}$ & $\mathrm{H}$ & $\mathrm{H}$ & $\mathrm{H}$ & $\mathrm{H}$ & $\mathrm{N}$ & $\mathrm{H}$ & $\mathrm{N}$ & $\mathrm{N}$ & $\mathrm{L}$ & $\mathrm{L}$ & $\mathrm{L}$ & $\mathrm{L}$ \\
\hline DM4 & $\mathrm{N}$ & $\mathrm{N}$ & $\mathrm{H}$ & $\mathrm{N}$ & $\mathrm{H}$ & $\mathrm{N}$ & $\mathrm{H}$ & $\mathrm{H}$ & $\mathrm{H}$ & $\mathrm{H}$ & $\mathrm{H}$ & $\mathrm{N}$ & $\mathrm{L}$ & $\mathrm{L}$ & $\mathrm{H}$ & $\mathrm{H}$ \\
\hline DM5 & $\mathrm{H}$ & $\mathrm{N}$ & $\mathrm{L}$ & $\mathrm{N}$ & $\mathrm{H}$ & $\mathrm{N}$ & $\mathrm{L}$ & $\mathrm{L}$ & $\mathrm{H}$ & $\mathrm{H}$ & $\mathrm{H}$ & $\mathrm{L}$ & $\mathrm{L}$ & $\mathrm{L}$ & $\mathrm{H}$ & $\mathrm{H}$ \\
\hline DM6 & $\mathrm{H}$ & $\mathrm{H}$ & $\mathrm{L}$ & $\mathrm{N}$ & $\mathrm{N}$ & $\mathrm{N}$ & $\mathrm{N}$ & $\mathrm{N}$ & $\mathrm{H}$ & $\mathrm{H}$ & $\mathrm{H}$ & $\mathrm{N}$ & $\mathrm{L}$ & $\mathrm{L}$ & $\mathrm{N}$ & $\mathrm{N}$ \\
\hline DM7 & $\mathrm{H}$ & $\mathrm{H}$ & $\mathrm{L}$ & $\mathrm{L}$ & $\mathrm{N}$ & $\mathrm{N}$ & $\mathrm{N}$ & $\mathrm{H}$ & $\mathrm{H}$ & $\mathrm{N}$ & $\mathrm{H}$ & $\mathrm{L}$ & $\mathrm{L}$ & $\mathrm{L}$ & $\mathrm{N}$ & $\mathrm{H}$ \\
\hline DM8 & $\mathrm{N}$ & $\mathrm{N}$ & $\mathrm{H}$ & $\mathrm{N}$ & $\mathrm{L}$ & $\mathrm{N}$ & $\mathrm{H}$ & $\mathrm{N}$ & $\mathrm{H}$ & $\mathrm{H}$ & $\mathrm{L}$ & $\mathrm{N}$ & $\mathrm{L}$ & $\mathrm{L}$ & $\mathrm{H}$ & $\mathrm{N}$ \\
\hline DM9 & $\mathrm{N}$ & $\mathrm{L}$ & $\mathrm{H}$ & $\mathrm{L}$ & $\mathrm{N}$ & $\mathrm{L}$ & $\mathrm{N}$ & $\mathrm{H}$ & $\mathrm{L}$ & $\mathrm{H}$ & $\mathrm{H}$ & $\mathrm{L}$ & $\mathrm{L}$ & $\mathrm{L}$ & $\mathrm{N}$ & $\mathrm{L}$ \\
\hline DM10 & $\mathrm{N}$ & $\mathrm{H}$ & $\mathrm{N}$ & $\mathrm{N}$ & $\mathrm{H}$ & $\mathrm{H}$ & $\mathrm{N}$ & $\mathrm{H}$ & $\mathrm{H}$ & $\mathrm{L}$ & $\mathrm{H}$ & $\mathrm{L}$ & $\mathrm{H}$ & $\mathrm{L}$ & $\mathrm{H}$ & $\mathrm{H}$ \\
\hline DM11 & $\mathrm{H}$ & $\mathrm{H}$ & $\mathrm{N}$ & $\mathrm{H}$ & $\mathrm{N}$ & $\mathrm{N}$ & $\mathrm{H}$ & $\mathrm{N}$ & $\mathrm{L}$ & $\mathrm{H}$ & $\mathrm{H}$ & $\mathrm{H}$ & $\mathrm{N}$ & $\mathrm{L}$ & $\mathrm{N}$ & $\mathrm{N}$ \\
\hline DM12 & $\mathrm{H}$ & $\mathrm{H}$ & $\mathrm{N}$ & $\mathrm{N}$ & $\mathrm{N}$ & $\mathrm{N}$ & $\mathrm{H}$ & $\mathrm{N}$ & $\mathrm{H}$ & $\mathrm{H}$ & $\mathrm{N}$ & $\mathrm{H}$ & $\mathrm{N}$ & $\mathrm{H}$ & $\mathrm{L}$ & $\mathrm{N}$ \\
\hline DM13 & $\mathrm{N}$ & $\mathrm{H}$ & $\mathrm{H}$ & $\mathrm{N}$ & $\mathrm{L}$ & $\mathrm{N}$ & $\mathrm{L}$ & $\mathrm{H}$ & $\mathrm{H}$ & $\mathrm{H}$ & $\mathrm{H}$ & $\mathrm{N}$ & $\mathrm{L}$ & $\mathrm{L}$ & $\mathrm{H}$ & $\mathrm{N}$ \\
\hline DM14 & $\mathrm{L}$ & $\mathrm{N}$ & $\mathrm{L}$ & $\mathrm{N}$ & $\mathrm{L}$ & $\mathrm{L}$ & $\mathrm{H}$ & $\mathrm{L}$ & $\mathrm{H}$ & $\mathrm{H}$ & $\mathrm{H}$ & $\mathrm{N}$ & $\mathrm{N}$ & $\mathrm{L}$ & $\mathrm{H}$ & $\mathrm{H}$ \\
\hline \multirow[t]{2}{*}{ Decision maker } & $\mathrm{C} 7$ & $\mathrm{C} 8$ & & & & & & & & & & & & & & \\
\hline & A1 & A2 & A3 & A4 & A5 & A6 & A7 & A8 & A1 & A2 & A3 & $\mathrm{A} 4$ & A5 & A6 & A7 & A8 \\
\hline DM1 & B & $\mathrm{G}$ & $\mathrm{N}$ & G & B & $\mathrm{N}$ & $\mathrm{B}$ & $\mathrm{G}$ & $\mathrm{L}$ & $\mathrm{N}$ & $\mathrm{L}$ & $\mathrm{H}$ & $\mathrm{N}$ & $\mathrm{L}$ & $\mathrm{L}$ & $\mathrm{H}$ \\
\hline DM2 & B & $\mathrm{N}$ & $\mathrm{G}$ & $\mathrm{N}$ & $\mathrm{N}$ & $\mathrm{N}$ & $\mathrm{G}$ & $\mathrm{N}$ & $\mathrm{N}$ & $\mathrm{N}$ & $\mathrm{H}$ & $\mathrm{H}$ & $\mathrm{L}$ & $\mathrm{N}$ & $\mathrm{H}$ & $\mathrm{H}$ \\
\hline DM3 & $\mathrm{N}$ & G & $\mathrm{N}$ & G & $\mathrm{N}$ & $\mathrm{N}$ & $\mathrm{N}$ & G & $\mathrm{N}$ & $\mathrm{H}$ & $\mathrm{N}$ & $\mathrm{H}$ & $\mathrm{N}$ & $\mathrm{H}$ & $\mathrm{N}$ & $\mathrm{N}$ \\
\hline DM4 & $\mathrm{N}$ & G & $\mathrm{N}$ & $\mathrm{N}$ & $\mathrm{N}$ & $\mathrm{N}$ & $\mathrm{N}$ & $\mathrm{N}$ & $\mathrm{N}$ & $\mathrm{H}$ & $\mathrm{N}$ & $\mathrm{N}$ & $\mathrm{N}$ & $\mathrm{N}$ & $\mathrm{L}$ & $\mathrm{N}$ \\
\hline DM5 & $\mathrm{N}$ & $\mathrm{N}$ & G & $\mathrm{N}$ & B & $\mathrm{N}$ & $\mathrm{N}$ & G & $\mathrm{H}$ & $\mathrm{N}$ & $\mathrm{N}$ & $\mathrm{L}$ & $\mathrm{N}$ & $\mathrm{N}$ & $\mathrm{H}$ & $\mathrm{N}$ \\
\hline DM6 & G & G & $\mathrm{N}$ & $\mathrm{N}$ & $\mathrm{N}$ & $\mathrm{N}$ & $\mathrm{N}$ & $\mathrm{G}$ & $\mathrm{N}$ & $\mathrm{N}$ & $\mathrm{H}$ & $\mathrm{N}$ & $\mathrm{N}$ & $\mathrm{N}$ & $\mathrm{H}$ & $\mathrm{N}$ \\
\hline DM7 & B & G & G & G & G & $\mathrm{N}$ & G & $\mathrm{N}$ & $\mathrm{H}$ & $\mathrm{H}$ & $\mathrm{L}$ & $\mathrm{N}$ & $\mathrm{N}$ & $\mathrm{N}$ & $\mathrm{L}$ & $\mathrm{L}$ \\
\hline DM8 & G & G & $\mathrm{N}$ & B & $\mathrm{N}$ & G & $\mathrm{N}$ & $\mathrm{N}$ & $\mathrm{H}$ & $\mathrm{H}$ & $\mathrm{H}$ & $\mathrm{N}$ & $\mathrm{H}$ & $\mathrm{N}$ & $\mathrm{H}$ & $\mathrm{H}$ \\
\hline DM9 & G & B & $\mathrm{N}$ & $\mathrm{N}$ & B & B & B & $\mathrm{N}$ & $\mathrm{H}$ & $\mathrm{H}$ & $\mathrm{L}$ & $\mathrm{N}$ & $\mathrm{N}$ & $\mathrm{L}$ & $\mathrm{L}$ & $\mathrm{H}$ \\
\hline DM10 & $\mathrm{N}$ & G & $\mathrm{N}$ & $\mathrm{N}$ & B & B & G & G & $\mathrm{N}$ & $\mathrm{H}$ & $\mathrm{L}$ & $\mathrm{N}$ & $\mathrm{N}$ & $\mathrm{N}$ & $\mathrm{L}$ & $\mathrm{L}$ \\
\hline DM11 & $\mathrm{N}$ & G & B & $\mathrm{N}$ & $\mathrm{N}$ & $\mathrm{N}$ & $\mathrm{N}$ & B & $\mathrm{H}$ & $\mathrm{H}$ & $\mathrm{H}$ & $\mathrm{N}$ & $\mathrm{N}$ & $\mathrm{N}$ & $\mathrm{N}$ & $\mathrm{H}$ \\
\hline
\end{tabular}


TABLE 5: Continued.

\begin{tabular}{|c|c|c|c|c|c|c|c|c|c|c|c|c|c|c|c|c|}
\hline \multirow{2}{*}{ Decision maker } & \multicolumn{8}{|c|}{$\mathrm{C} 1$} & \multicolumn{8}{|c|}{$\mathrm{C} 2$} \\
\hline & A1 & A2 & A3 & A4 & A5 & A6 & A7 & A8 & A1 & A2 & A3 & A4 & A5 & A6 & A7 & A8 \\
\hline DM12 & $\mathrm{N}$ & G & G & $\mathrm{N}$ & $\mathrm{N}$ & $\mathrm{N}$ & G & $\mathrm{N}$ & $\mathrm{L}$ & $\mathrm{N}$ & $\mathrm{N}$ & $\mathrm{N}$ & $\mathrm{N}$ & $\mathrm{N}$ & $\mathrm{N}$ & $\mathrm{N}$ \\
\hline DM13 & G & G & $\mathrm{N}$ & $\mathrm{N}$ & $\mathrm{N}$ & B & G & $\mathrm{N}$ & $\mathrm{H}$ & $\mathrm{L}$ & $\mathrm{N}$ & $\mathrm{N}$ & $\mathrm{N}$ & $\mathrm{N}$ & $\mathrm{L}$ & $\mathrm{H}$ \\
\hline DM14 & $\mathrm{N}$ & G & G & G & $\mathrm{B}$ & $\mathrm{N}$ & $\mathrm{N}$ & $\mathrm{B}$ & $\mathrm{N}$ & $\mathrm{L}$ & $\mathrm{L}$ & $\mathrm{H}$ & $\mathrm{L}$ & $\mathrm{L}$ & $\mathrm{L}$ & $\mathrm{L}$ \\
\hline
\end{tabular}

Note: the colors are representing the nature of the criteria; green: maximizing criteria and red: minimizing criteria.

As described in Step 24 (Section 3.4), the average solution AV is calculated using the following expression [86]:

$$
A V=\left[A V_{j}\right]_{1 \times n}=\left\{1-\prod_{i=1}^{m}\left(1-\mu_{i j}\right)^{1 / m}, \prod_{i=1}^{m}\left(\eta_{i j}\right)^{1 / m}, \prod_{i=1}^{m}\left(v_{i j}\right)^{1 / m}\right\}_{1 \times n},
$$

$\left\{\mu_{i j}, \eta_{i j}, v_{i j}^{\prime}\right\}$ are the elements of the PIS matrix.

Step 34. Calculation of distance of each alternative solution from each of the PIS.

We calculate the Euclidean distances using expression (12) for each alternative from each of the PIS as found in Step 33.

Step 35. Calculation of distance of each alternative from the average solution.

Now, in a similar way, using expression (12), we calculate the distance of each alternative from the average solution as derived in Step 34.

Step 36. Calculation of the overall positive ideal distance (OPID) and overall negative ideal distance (ONID)

In our study, a total of eight alternatives and eight criteria are considered. Therefore, using the expressions (30) and (31) with $m=8$ (even number), we calculate OPID and ONID.

Step 37. Calculation of OPID to ONID ratio.

In the next step, we determine $R_{i}$ values for each alternative using expression (32).

Step 38. Determine the final performance score.
The $P S_{i}$ values are derived using expression (33), and the alternatives are ranked. The alternative whose $P S_{i}$ value is the highest is ranked first and so on.

\section{Results and Discussion}

After aggregating the responses of all DMs considering the proportion of the type of responses (positive, neutral, and negative) [85], we get the PF rating matrix as given in Table 6.

Now, we proceed to find the absolute and actual scores of the criteria as mentioned in Step 23 (Section 3.5) using the expressions from (15) to (20). Table 7 exhibits the values of the PGD, NGD, absolute scores (Abs_Score), and actual scores (Act_Score) for the criteria $C_{1}, C_{2}, C_{3}, \ldots, C_{8}$. Here, the average of $\eta$ values (Avg_ $\eta$ ) is 0.313 , and the PIS $\left(Z^{+}\right)$is found as $(0.786,0.143,0.071)$.

Now, we order the criteria as per the preferences of the DMs (as per Act_Score values). It may be noted that $\mathrm{C}_{1}$ and $\mathrm{C}_{2}$ hold equal Act_Score values. Let us consider that $\mathrm{C}_{1}$ is the most preferred criterion over the others. The descending order of the criteria starting from $\mathrm{C}_{1}$ is, $\mathrm{C}_{1}>\mathrm{C}_{2}>\mathrm{C}_{3}>\mathrm{C}_{4}>\mathrm{C}_{7}>\mathrm{C}_{8}>\mathrm{C}_{5}>\mathrm{C}_{6}$

Next, we move to derive the CP of the criteria and carry out a comparison of the criteria. Table 8 shows the CP of the criteria and the results of checking of the conditions as per expressions (34) and (35). The final LP-based model is 
TABLE 6: Criteria rating matrix in terms of PFNs (calculated by aggregating responses on linguistic scales).

\begin{tabular}{lccr}
\hline Criteria & & PFN & \\
& $\mu$ & $\eta$ & 0.071 \\
C1 & 0.786 & 0.143 & 0.071 \\
C2 & 0.786 & 0.214 & 0.071 \\
C3 & 0.714 & 0.286 & 0.143 \\
C4 & 0.571 & 0.429 & 0.214 \\
C5 & 0.357 & 0.357 & 0.429 \\
C6 & 0.214 & 0.429 & 0.071 \\
C7 & 0.500 & 0.500 & 0.143 \\
C8 & 0.357 & . & \\
\hline
\end{tabular}

Note: the colors are representing the nature of the criteria; green: maximizing criteria and red: minimizing criteria.

TABLE 7: Absolute and actual scores of respective PFNs representing the criteria.

\begin{tabular}{lcccc}
\hline Criteria & PGD & NGD & Abs_Score & Act_Score \\
\hline C1 & 0.000 & 0.000 & 1.000 & 1.20430 \\
C2 & 0.000 & 0.000 & 1.000 & 1.20430 \\
C3 & 0.071 & 0.000 & 0.929 & 1.02970 \\
C4 & 0.214 & 0.071 & 0.714 & 0.73394 \\
C5 & 0.429 & 0.143 & 0.429 & 0.38400 \\
C6 & 0.571 & 0.357 & 0.071 & 0.06838 \\
C7 & 0.286 & 0.000 & 0.714 & 0.64000 \\
C8 & 0.429 & 0.071 & 0.500 & 0.42105 \\
\hline
\end{tabular}

TABLE 8: Comparative priority of the criteria.

\begin{tabular}{lcccc}
\hline Criteria & Priority & $\varnothing_{(k / k+1)}$ & $\left(W_{k} / W_{k+1}\right)$ & $\left(W_{k} / W_{k+2}\right)$ \\
\hline C1 & 1.2043 & 1.0000 & 1.0000 & 1.1696 \\
C2 & 1.2043 & 1.1696 & 1.1696 & 1.6409 \\
C3 & 1.0297 & 1.4030 & 1.4030 & 1.6089 \\
C4 & 0.7339 & 1.1468 & 1.1468 & 1.7431 \\
C7 & 0.6400 & 1.5200 & 1.5200 & 1.6667 \\
C8 & 0.4211 & 1.0965 & 1.0965 & 6.1579 \\
C5 & 0.3840 & 5.6160 & 5.6160 & \\
C6 & 0.0684 & & & \\
\hline
\end{tabular}

formulated as per expression (36) for obtaining the criteria weights and is given in expression (55).

$\operatorname{Min} \chi$

$$
\text { S.T. }\left\{\begin{array}{l}
\left|\frac{w_{1}}{w_{2}}\right|-1.0000 \leq \chi ;\left|\frac{w_{2}}{w_{3}}\right|-1.1696 \leq \chi ;\left|\frac{w_{3}}{w_{4}}\right|-1.4030 \leq \chi ;\left|\frac{w_{4}}{w_{7}}\right|-1.1468 \leq \chi ; \\
\left|\frac{w_{7}}{w_{8}}\right|-1.5200 \leq \chi ;\left|\frac{w_{8}}{w_{5}}\right|-1.0965 \leq \chi ;\left|\frac{w_{5}}{w_{6}}\right|-5.6160 \leq \chi, \\
\left|\frac{w_{7}}{w_{5}}\right|-1.6667 \leq \chi ;\left|\frac{w_{8}}{w_{6}}\right|-6.1579 \leq \chi, \\
\sum_{j=1}^{8} w_{j}=1 ; w_{j} \geq 0 \forall j .
\end{array}\right.
$$

Now, we solve the expression (42) using Lingo 19 software and obtain the criteria weights as mentioned in Table 9.
The DFC $(\chi)$ value is calculated as $\chi=0.00001701 \approx 0$, which indicates the validity of the criteria weight calculation using PF-FUCOM. We observe that $\mathrm{C} 1$ and $\mathrm{C} 2$ 
TABle 9: Criteria weights.

\begin{tabular}{ccccccccc}
\hline Criteria & C1 & C2 & C3 & C4 & C5 & C6 & C7 & C8 \\
\hline Weight & 0.2120 & 0.2120 & 0.1810 & 0.1290 & 0.0660 & 0.0120 & 0.1130 & 0.0740 \\
\hline
\end{tabular}

C1: user friendliness; C2: compatibility; C3: quality of transmission; C4: features; C5: bandwidth consumption; C6: awareness; C7: security and privacy; C8: cost.

hold the same weight values. It is noticed that $C_{1} \approx C_{2}>C_{3}>C_{4}>C_{7}>C_{8}>C_{5}>C_{6}$.

We find that the users have given more emphasis on the ease of operations, compatibility with multiple systems and devices, quality of the voice and video transmission, and features, which is in sync with the general propositions of usability and UX theory.

Now, we move to rank the VC platforms under comparison. For that, we obtain the rating of the DMs for the alternatives subject to the criteria for comparison. After aggregating the responses in the same way as we did for the $\mathrm{PF}$ rating matrix, we construct $\mathrm{PF}-\mathrm{DMT}$, which is given in Table 10 .

Next, we normalize PF-DMT and construct the weighted NPF-DMT as described in Steps 10 and 11 (Section 3.5) using the expressions (6) and (51-53). Table 11 provides the weighted NPF-DMT.

Next, we find the PIS values as described in Step 22 (Section 3.5) using the expression (12). Table 12 exhibits the PIS values for the alternatives subject to the criteria.

Now, we follow Steps 23 and 24 (Section 3.5) for deciding the final order of the VCs under comparison. Table 13 shows the distance values of the alternatives with respect to the PIS and the average solution point. Table 14 highlights the OPID, ONID, $R_{\mathrm{I}}$, and $\mathrm{PS}_{\mathrm{i}}$ values and the final ranks of the VCs.

It is seen that $A_{3}>A_{1}>A_{2}>A_{7}>A_{4}>A_{8}>A_{5}>A_{6}$. Hence, Google Meet, Zoom, and Microsoft Teams are found to be more popular than others. However, being a more sophisticated tool, Webex stands at position 5 because of its cost element. It is interesting to note that WhatsApp holds the $4^{\text {th }}$ position perhaps because of its wide availability and better mobility.

4.1. Validation. The reliability of the results obtained from any MCDM model depends on various underlying assumptions, such as criteria selection and their interrelationship, choice of the algorithm given the context and its ability to reflect the true picture, variations in the criteria weights, change in the alternative and criteria, and so on $[87,88]$. Hence, it is necessary to carry out the validation test for ensuring the robustness and stability in the final solution [89-91]. We check the validity in the following ways:

(a) Comparing the results obtained from our method with those derived using other established algorithms [92-95].

(b) Checking for rank reversal test. Rank reversal is a phenomenon, wherein the original order of the alternatives gets disturbed with the effect of change in the given conditions, e.g., change in the alternative set. In effect, we get an illogical and unreliable result [96].

In the present study, we carry out the comparative analysis of the VC platforms using the PF-TOPSIS method [97] and MABAC [98] algorithm using the actual scores of PFNs. Table 15 shows that there are no variations in the comparative positions of the alternatives. Figure 2 reflects the findings.

To test the existence of any rank reversal phenomenon, we deliberately remove alternative $A_{2}$ from the list and carry out the comparative analysis using the PF-FUCOM-PROBID model. Following are the findings:

$$
\begin{array}{lll}
\begin{array}{l}
\text { Original } \quad \text { ranking } \\
A_{3}>A_{1}>A_{2}>A_{7}>A_{4}>A_{8}>A_{5}>A_{6}
\end{array} & \left.A_{2}\right): \\
\text { New } \quad \text { ranking } \quad \text { (without } & \left.A_{2}\right): \\
A_{3}>A_{1}>A_{7}>A_{4}>A_{8}>A_{5}>A_{6} &
\end{array}
$$

The findings clearly suggest that there is no evidence of rank reversal. Hence, we may conclude that our model provides valid and reliable results.

4.2. Sensitivity Analysis. Sensitivity analysis is carried out to check the extent the original ranking provided by a MCDM model may get distorted because of the variations in the given conditions, and thereby, ascertaining the robustness and stability in the results [99-101]. There are a number of ways the sensitivity analysis is performed in the extant literature, such as proportionate change in the criteria weights, while maintaining the sum of the weights equal to 1 , exchange of weights among the criteria, and so on [96, 101, 102].

In this paper, we generate the following scenarios:

(i) Decrease the weight of C1 (highest priority criterion) by $10 \%$ and adjust the amount of decrease in the total weight by increasing the weights of other criteria proportionately for ensuring the sum of weights $=1$

(ii) Decrease the weight of C3 (the next highest priority criterion) by $10 \%$ and adjust the amount of decrease in the total weight by increasing the weights of other criteria proportionately for ensuring the sum of weights $=1$

(iii) Increase the weight of $\mathrm{C} 1$ (highest priority criterion) by $10 \%$ and adjust the amount of increase in the total weight by decreasing the weights of other criteria proportionately for ensuring the sum of weights $=1$

(iv) Increase the weight of C3 (the next highest priority criterion) by $10 \%$ and adjust the amount of increase 
TABle 10: Decision matrix expressed in the PF domain.

\begin{tabular}{|c|c|c|c|c|c|c|c|c|c|c|c|c|}
\hline VC type & & C1 & & & C2 & & & C3 & & & C4 & \\
\hline $\mathrm{A} 1$ & 0.643 & 0.286 & 0.071 & 0.786 & 0.143 & 0.071 & 0.571 & 0.357 & 0.071 & 0.571 & 0.214 & 0.214 \\
\hline $\mathrm{A} 2$ & 0.500 & 0.429 & 0.071 & 0.571 & 0.357 & 0.071 & 0.643 & 0.286 & 0.071 & 0.643 & 0.286 & 0.071 \\
\hline A3 & 0.786 & 0.143 & 0.071 & 0.714 & 0.143 & 0.143 & 0.714 & 0.214 & 0.071 & 0.571 & 0.286 & 0.143 \\
\hline A4 & 0.143 & 0.429 & 0.429 & 0.357 & 0.500 & 0.143 & 0.500 & 0.286 & 0.214 & 0.357 & 0.500 & 0.143 \\
\hline A5 & 0.071 & 0.714 & 0.214 & 0.071 & 0.714 & 0.214 & 0.071 & 0.643 & 0.286 & 0.143 & 0.500 & 0.357 \\
\hline A6 & 0.071 & 0.643 & 0.286 & 0.071 & 0.571 & 0.357 & 0.071 & 0.643 & 0.286 & 0.071 & 0.571 & 0.357 \\
\hline A7 & 0.714 & 0.214 & 0.071 & 0.500 & 0.214 & 0.286 & 0.357 & 0.357 & 0.286 & 0.214 & 0.429 & 0.357 \\
\hline A8 & 0.071 & 0.571 & 0.357 & 0.357 & 0.429 & 0.214 & 0.357 & 0.429 & 0.214 & 0.214 & 0.643 & 0.143 \\
\hline VC type & & C5 & & & C6 & & & C7 & & & C8 & \\
\hline A1 & 0.429 & 0.357 & 0.214 & 0.714 & 0.143 & 0.143 & 0.286 & 0.500 & 0.214 & 0.429 & 0.429 & 0.143 \\
\hline $\mathrm{A} 2$ & 0.500 & 0.429 & 0.071 & 0.786 & 0.143 & 0.071 & 0.786 & 0.143 & 0.071 & 0.500 & 0.357 & 0.143 \\
\hline A3 & 0.429 & 0.214 & 0.357 & 0.786 & 0.143 & 0.071 & 0.357 & 0.571 & 0.071 & 0.286 & 0.357 & 0.357 \\
\hline $\mathrm{A} 4$ & 0.214 & 0.643 & 0.143 & 0.214 & 0.500 & 0.286 & 0.286 & 0.643 & 0.071 & 0.286 & 0.643 & 0.071 \\
\hline A5 & 0.286 & 0.500 & 0.214 & 0.071 & 0.500 & 0.571 & 0.071 & 0.571 & 0.357 & 0.071 & 0.786 & 0.143 \\
\hline A6 & 0.143 & 0.714 & 0.143 & 0.143 & 0.071 & 0.786 & 0.071 & 0.714 & 0.214 & 0.071 & 0.714 & 0.214 \\
\hline A7 & 0.500 & 0.357 & 0.143 & 0.571 & 0.286 & 0.143 & 0.357 & 0.500 & 0.143 & 0.286 & 0.214 & 0.500 \\
\hline A8 & 0.429 & 0.429 & 0.143 & 0.500 & 0.357 & 0.143 & 0.357 & 0.500 & 0.143 & 0.429 & 0.357 & 0.214 \\
\hline
\end{tabular}

Note: the colors are representing the nature of the criteria; green: maximizing criteria and red: minimizing criteria.

TABLE 11: Weighted normalized PF-DMT (NPF-DMT).

\begin{tabular}{lccccccccccccc}
\hline Criteria/alternatives & & $\mathrm{C} 1$ & & \multicolumn{3}{c}{$\mathrm{C} 2$} & & & $\mathrm{C} 3$ & & $\mathrm{C} 4$ \\
\hline A1 & 0.1363 & 0.0606 & 0.0151 & 0.1666 & 0.0303 & 0.0151 & 0.1034 & 0.0646 & 0.0129 & 0.0737 & 0.0276 & 0.0276 \\
A2 & 0.1060 & 0.0909 & 0.0151 & 0.1211 & 0.0757 & 0.0151 & 0.1164 & 0.0517 & 0.0129 & 0.0829 & 0.0369 & 0.0092 \\
A3 & 0.1666 & 0.0303 & 0.0151 & 0.1514 & 0.0303 & 0.0303 & 0.1293 & 0.0388 & 0.0129 & 0.0737 & 0.0369 & 0.0184 \\
A4 & 0.0303 & 0.0909 & 0.0909 & 0.0757 & 0.1060 & 0.0303 & 0.0905 & 0.0517 & 0.0388 & 0.0461 & 0.0645 & 0.0184 \\
A5 & 0.0151 & 0.1514 & 0.0454 & 0.0151 & 0.1514 & 0.0454 & 0.0129 & 0.1164 & 0.0517 & 0.0184 & 0.0645 & 0.0461 \\
A6 & 0.0151 & 0.1363 & 0.0606 & 0.0151 & 0.1211 & 0.0757 & 0.0129 & 0.1164 & 0.0517 & 0.0092 & 0.0737 & 0.0461 \\
A7 & 0.1514 & 0.0454 & 0.0151 & 0.1060 & 0.0454 & 0.0606 & 0.0646 & 0.0646 & 0.0517 & 0.0276 & 0.0553 & 0.0461 \\
A8 & 0.0151 & 0.1211 & 0.0757 & 0.0757 & 0.0909 & 0.0454 & 0.0646 & 0.0776 & 0.0388 & 0.0276 & 0.0829 & 0.0184 \\
Criteria/alternatives & & C5 & & & C6 & & & C7 & & & & & \\
A1 & 0.0141 & 0.0236 & 0.0283 & 0.0086 & 0.0017 & 0.0017 & 0.0323 & 0.0565 & 0.0242 & 0.0106 & 0.0317 & 0.0317 \\
A2 & 0.0047 & 0.0283 & 0.0330 & 0.0094 & 0.0017 & 0.0009 & 0.0888 & 0.0161 & 0.0081 & 0.0106 & 0.0264 & 0.0370 \\
A3 & 0.0236 & 0.0141 & 0.0283 & 0.0094 & 0.0017 & 0.0009 & 0.0404 & 0.0646 & 0.0081 & 0.0264 & 0.0264 & 0.0211 \\
A4 & 0.0094 & 0.0424 & 0.0141 & 0.0026 & 0.0060 & 0.0034 & 0.0323 & 0.0726 & 0.0081 & 0.0053 & 0.0476 & 0.0211 \\
A5 & 0.0141 & 0.0330 & 0.0189 & 0.0009 & 0.0060 & 0.0069 & 0.0081 & 0.0646 & 0.0404 & 0.0106 & 0.0581 & 0.0053 \\
A6 & 0.0094 & 0.0471 & 0.0094 & 0.0017 & 0.0009 & 0.0094 & 0.0081 & 0.0807 & 0.0242 & 0.0159 & 0.0529 & 0.0053 \\
A7 & 0.0094 & 0.0236 & 0.0330 & 0.0069 & 0.0034 & 0.0017 & 0.0404 & 0.0565 & 0.0161 & 0.0370 & 0.0159 & 0.0211 \\
A8 & 0.0094 & 0.0283 & 0.0283 & 0.0060 & 0.0043 & 0.0017 & 0.0404 & 0.0565 & 0.0161 & 0.0159 & 0.0264 & 0.0317 \\
\hline
\end{tabular}

Note: the colors are representing the nature of the criteria; green: maximizing and red: minimizing criteria.

TABLE 12: PIS values.

\begin{tabular}{|c|c|c|c|c|c|c|c|c|c|c|c|c|c|}
\hline \multirow[b]{2}{*}{$1^{\text {st }}$ PIS (i.e., most PIS) } & \multicolumn{2}{|l|}{ PIS } & \multicolumn{2}{|l|}{$\mathrm{C} 1$} & \multicolumn{3}{|c|}{$\mathrm{C} 2$} & \multicolumn{3}{|c|}{ C3 } & \multicolumn{3}{|c|}{$\mathrm{C} 4$} \\
\hline & PIS 1 & 0.1666 & 0.0303 & 0.0151 & 0.1666 & 0.0303 & 0.0151 & 0.1293 & 0.0388 & 0.0129 & 0.0829 & 0.0276 & 0.0092 \\
\hline $2^{\text {nd }}$ PIS & PIS 2 & 0.1514 & 0.0454 & 0.0151 & 0.1514 & 0.0303 & 0.0151 & 0.1164 & 0.0517 & 0.0129 & 0.0737 & 0.0369 & 0.0184 \\
\hline \multirow[t]{5}{*}{$3^{\text {rd }}$ PIS } & PIS 3 & 0.1363 & 0.0606 & 0.0151 & 0.1211 & 0.0454 & 0.0303 & 0.1034 & 0.0517 & 0.0129 & 0.0737 & 0.0369 & 0.0184 \\
\hline & PIS 4 & 0.1060 & 0.0909 & 0.0151 & 0.1060 & 0.0757 & 0.0303 & 0.0905 & 0.0646 & 0.0388 & 0.0461 & 0.0553 & 0.0184 \\
\hline & PIS 5 & 0.0303 & 0.0909 & 0.0454 & 0.0757 & 0.0909 & 0.0454 & 0.0646 & 0.0646 & 0.0388 & 0.0276 & 0.0645 & 0.0276 \\
\hline & PIS 6 & 0.0151 & 0.1211 & 0.0606 & 0.0757 & 0.1060 & 0.0454 & 0.0646 & 0.0776 & 0.0517 & 0.0276 & 0.0645 & 0.0461 \\
\hline & PIS 7 & 0.0151 & 0.1363 & 0.0757 & 0.0151 & 0.1211 & 0.0606 & 0.0129 & 0.1164 & 0.0517 & 0.0184 & 0.0737 & 0.0461 \\
\hline Most NIS & $\begin{array}{c}\text { PIS } 8 \\
\text { PIS }\end{array}$ & 0.0151 & $\begin{array}{c}0.1514 \\
\text { C5 }\end{array}$ & 0.0909 & & $\begin{array}{c}0.1514 \\
\text { C6 }\end{array}$ & & & $\begin{array}{c}0.1164 \\
\text { C7 }\end{array}$ & & 0.0092 & $\begin{array}{c}0.0829 \\
\text { C8 }\end{array}$ & \\
\hline $1^{\text {st }}$ PIS (i.e., most PIS) & PIS 1 & 0.0236 & 0.0141 & 0.0094 & 0.0094 & 0.0009 & 0.0009 & 0.0888 & 0.0161 & 0.0081 & 0.0370 & 0.0159 & 0.0053 \\
\hline $2^{\text {nd }}$ PIS & PIS 2 & 0.0141 & 0.0236 & 0.0141 & 0.0094 & 0.0017 & 0.0009 & 0.0404 & 0.0565 & 0.0081 & 0.0264 & 0.0264 & 0.0053 \\
\hline \multirow[t]{5}{*}{$3^{\text {rd }}$ PIS } & PIS 3 & 0.0141 & 0.0236 & 0.0189 & 0.0086 & 0.0017 & 0.0017 & 0.0404 & 0.0565 & 0.0081 & 0.0159 & 0.0264 & 0.0211 \\
\hline & PIS 4 & 0.0094 & 0.0283 & 0.0283 & 0.0069 & 0.0017 & 0.0017 & 0.0404 & 0.0565 & 0.0161 & 0.0159 & 0.0264 & 0.0211 \\
\hline & PIS 5 & 0.0094 & 0.0283 & 0.0283 & 0.0060 & 0.0034 & 0.0017 & 0.0323 & 0.0646 & 0.0161 & 0.0106 & 0.0317 & 0.0211 \\
\hline & PIS 6 & 0.0094 & 0.0330 & 0.0283 & 0.0026 & 0.0043 & 0.0034 & 0.0323 & 0.0646 & 0.0242 & 0.0106 & 0.0476 & 0.0317 \\
\hline & PIS 7 & 0.0094 & 0.0424 & 0.0330 & 0.0017 & 0.0060 & 0.0069 & 0.0081 & 0.0726 & 0.0242 & 0.0106 & 0.0529 & 0.0317 \\
\hline Most NIS & PIS 8 & 0.0047 & 0.0471 & 0.0330 & 0.0009 & 0.0060 & 0.0094 & 0.0081 & 0.0807 & 0.0404 & 0.0053 & 0.0581 & 0.0370 \\
\hline
\end{tabular}


TABLE 13: Distance values of each alternative from the PIS and average solution.

\begin{tabular}{lccccccccc}
\hline \multirow{2}{*}{ VC type } & \multicolumn{9}{c}{ Distance from PIS \# } \\
& 1 & 2 & 3 & 4 & 5 & 6 & 7 & 8 & Distance from avg. solution \\
\hline A1 & 0.10422 & 0.05193 & 0.0586651 & 0.10291 & 0.1785 & 0.20684 & 0.27749 & 0.30472 & 0.1180 \\
A2 & 0.12171 & 0.11391 & 0.0887917 & 0.09009 & 0.15321 & 0.17765 & 0.25227 & 0.27726 & 0.1055 \\
A3 & 0.07896 & 0.04143 & 0.0652824 & 0.12673 & 0.20519 & 0.23986 & 0.30885 & 0.33532 & 0.1444 \\
A4 & 0.23892 & 0.19737 & 0.1653009 & 0.12223 & 0.06792 & 0.07522 & 0.14386 & 0.16437 & 0.0988 \\
A5 & 0.34357 & 0.29917 & 0.2619837 & 0.2018 & 0.13961 & 0.1137 & 0.06117 & 0.07208 & 0.1817 \\
A6 & 0.33947 & 0.29238 & 0.2554872 & 0.19882 & 0.12938 & 0.10887 & 0.04411 & 0.0645 & 0.1745 \\
A7 & 0.15199 & 0.11339 & 0.0941239 & 0.09224 & 0.15028 & 0.18325 & 0.23285 & 0.26011 & 0.1006 \\
A8 & 0.25753 & 0.21838 & 0.1837943 & 0.12758 & 0.05435 & 0.04936 & 0.11265 & 0.13675 & 0.1040 \\
\hline
\end{tabular}

TABLE 14: Ranking of the VCs.

\begin{tabular}{|c|c|c|c|c|c|}
\hline VC type & OPID & ONID & $R_{\mathrm{i}}$ & $\mathrm{PS}_{\mathrm{i}}$ & Rank \\
\hline $\mathrm{A} 1$ & 0.1755 & 0.5570 & 0.3150 & 1.0278 & 2 \\
\hline A2 & 0.2308 & 0.5009 & 0.4607 & 0.9304 & 3 \\
\hline A3 & 0.1531 & 0.6210 & 0.2466 & 1.0871 & 1 \\
\hline A4 & 0.4233 & 0.2784 & 1.5206 & 0.4007 & 5 \\
\hline A5 & 0.6309 & 0.1755 & 3.5957 & 0.2535 & 7 \\
\hline A6 & 0.6205 & 0.1552 & 3.9985 & 0.2334 & 8 \\
\hline A7 & 0.2631 & 0.4752 & 0.5537 & 0.8659 & 4 \\
\hline A 8 & 0.4599 & 0.2231 & 2.0612 & 0.2945 & 6 \\
\hline
\end{tabular}

TABLE 15: Results of the comparative analysis of results.

\begin{tabular}{lcccc}
\hline \multicolumn{2}{c}{ VC type } & & Rank \\
& & PF-PROBID & PF-TOPSIS & PF-MABAC \\
\hline A1 & Zoom & 2 & 2 & 2 \\
A2 & Microsoft Teams & 3 & 3 & 3 \\
A3 & Google Meet & 1 & 1 & 1 \\
A4 & Webex & 5 & 5 & 5 \\
A5 & GotoMeeting & 7 & 7 & 7 \\
A6 & We Chat & 8 & 8 & 4 \\
A7 & WhatsApp & 4 & 6 & 6 \\
A8 & Skype & 6 & 6 & 6 \\
\hline
\end{tabular}

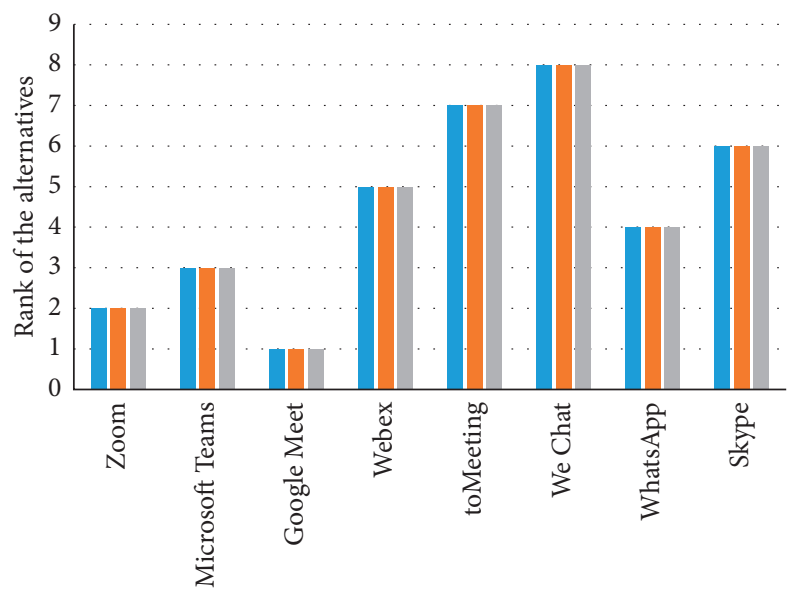

Alternatives

$$
\begin{array}{r}
\text { Series1 } \\
\text { - Series2 } \\
\text { - Series3 }
\end{array}
$$

Figure 2: Results of the comparison of results of different MCDM algorithms (Series 1: PF-PROBID; Series 2: PF-TOPSIS; Series 3: PF-MABAC). 
TABLe 16: Sensitivity analysis scenarios.

\begin{tabular}{lcccccccc}
\hline \multirow{2}{*}{ Scenario } & \multicolumn{9}{c}{ Criteria weights } & \multicolumn{2}{c}{ C6 } & C7 \\
\hline Original & 0.2120 & 0.2120 & 0.1810 & 0.1290 & 0.0660 & 0.0120 & 0.1130 \\
Case I & 0.1908 & 0.2150 & 0.1840 & 0.1320 & 0.0690 & 0.0150 & 0.1160 \\
Case II & 0.2146 & 0.2146 & 0.1629 & 0.1346 & 0.0716 & 0.0176 & 0.1186 & 0.0770 \\
Case III & 0.2332 & 0.2090 & 0.1780 & 0.1260 & 0.0630 & 0.0090 & 0.1100 & 0.0796 \\
Case IV & 0.2094 & 0.2094 & 0.1991 & 0.1264 & 0.0634 & 0.0094 & 0.1104 \\
Case V & 0.2118 & 0.2118 & 0.1808 & 0.1288 & 0.0658 & 0.0132 & 0.1128 \\
Case VI & 0.2111 & 0.2111 & 0.1801 & 0.1281 & 0.0726 & 0.0111 & 0.1121 & 0.0714 \\
\hline
\end{tabular}

in the total weight by decreasing the weights of other criteria proportionately for ensuring the sum of weights $=1$

(v) Increase the weight of C6 (the least priority criterion) by $10 \%$ and adjust the amount of increase in the total weight by decreasing the weights of other criteria proportionately for ensuring the sum of weights $=1$

(vi) Increase the weight of C5 (the minimizing criterion having low weight) by $10 \%$ and adjust the amount of increase in the total weight by decreasing the weights of other criteria proportionately for ensuring the sum of weights $=1$

Table 16 exhibits the different scenarios for sensitivity analysis. We carry out the comparative analysis of $\mathrm{VC}$ platforms under all the above-mentioned situations using the PF-PROBID method.

Table 17 confirms that there is no change in the comparative positions of the $\mathrm{VC}$ types despite variations in the criteria weights. Figure 3 also pictorially reflects the same fact. We further check for any significant variations in the performance scores for the alternatives obtained from various algorithms. Figure 4 confirms that there is no substantial variation too. Hence, we conclude that our model provides a notably robust and stable solution.

\section{Research Implications}

The present research provides a number of implications. Firstly, we have extended the fundamental model of PROBID method using PFN. PROBID is a useful method combining the features of two other powerful models, namely TOPSIS and EDAS. Within our limited search, we could not notice any single application of PROBID. The present paper shall provide a robust and reliable decision support framework to the researchers for solving complex real-life problems with imprecise information under uncertainty. Secondly, usability and UX are powerful frameworks for analyzing user behaviors. A plethora of work has been conducted using traditional models like TAM. Furthermore, the applications of UX so far have been restricted to the engineering domain. We believe that UX has a promising future for application in social science research. Thirdly, as we are moving toward a digitally operated world, there is a need to investigate from every perspective to define a user-friendly and technologically sound teaching-learning
TABLe 17: Result of sensitivity analysis.

\begin{tabular}{|c|c|c|c|c|c|c|c|}
\hline \multirow{2}{*}{$\begin{array}{l}\mathrm{VC} \\
\text { type }\end{array}$} & \multicolumn{7}{|c|}{ Ranking } \\
\hline & Original & $\begin{array}{c}\text { Case } \\
\text { I }\end{array}$ & $\begin{array}{c}\text { Case } \\
\text { II }\end{array}$ & $\begin{array}{c}\text { Case } \\
\text { III }\end{array}$ & $\begin{array}{c}\text { Case } \\
\text { IV }\end{array}$ & $\begin{array}{c}\text { Case } \\
\text { V }\end{array}$ & Case VI \\
\hline $\mathrm{A} 1$ & 2 & 2 & 2 & 2 & 2 & 2 & 2 \\
\hline $\mathrm{A} 2$ & 3 & 3 & 3 & 3 & 3 & 3 & 3 \\
\hline $\mathrm{A} 3$ & 1 & 1 & 1 & 1 & 1 & 1 & 1 \\
\hline A4 & 5 & 5 & 5 & 5 & 5 & 5 & 5 \\
\hline A5 & 7 & 7 & 7 & 7 & 7 & 7 & 7 \\
\hline A6 & 8 & 8 & 8 & 8 & 8 & 8 & 8 \\
\hline A7 & 4 & 4 & 4 & 4 & 4 & 4 & 4 \\
\hline A8 & 6 & 6 & 6 & 6 & 6 & 6 & 6 \\
\hline
\end{tabular}

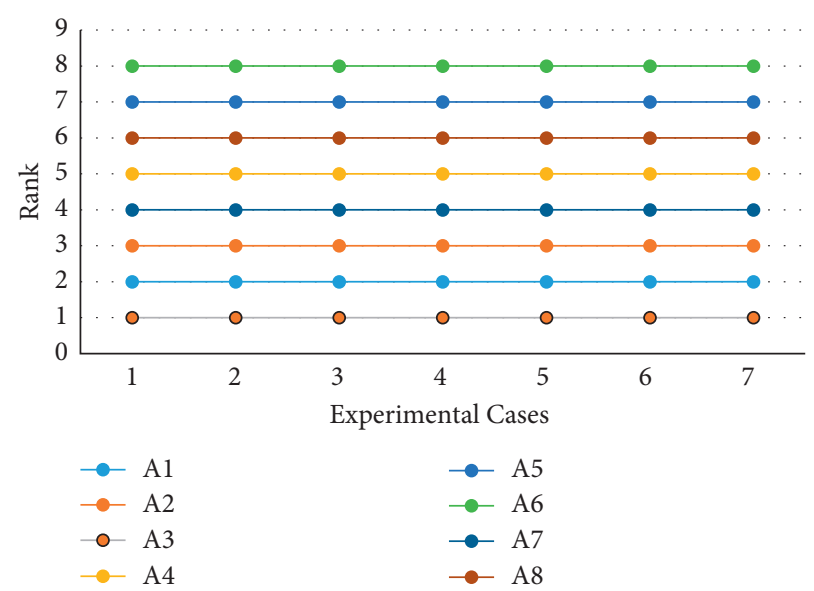

FIgURE 3: Sensitivity analysis.

mechanism. We address a contemporary problem of comparison of VC platforms in the context of higher education, which has undergone a paradigm shift with the effect of Covid-19. VC is a necessity today for education. In this regard, the present work provides a new perspective to the decision makers and policy makers. The findings of this paper suggest that the factors like wide availability, flexibility, cost, quality of transmission, and ease of use are required to be given emphasis for effective teaching and learning using VC tools. In this context, the present study allures us to investigate the criteria determining the efficacy of the teaching and learning using virtual media vis-à-vis its offline counterpart. It is evident that our model is useful in providing directions for effective management of virtual offices and workforces which would play critical roles for ensuring business success in future. 


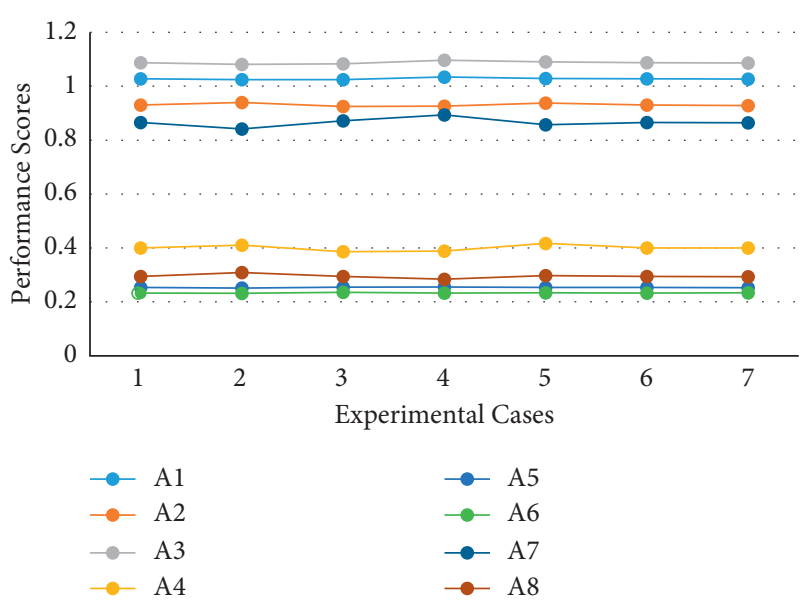

FIGURE 4: Variations in the performance scores during sensitivity analysis.

\section{Conclusion}

In this paper, we select a set of popular VC platforms used in higher education in India, such as Zoom, Microsoft Teams, Google Meet, Webex, GotoMeeting, We Chat, WhatsApp, and Skype. We use the theoretical foundation of usability and user experience (UX) and the opinions of the past work to identify eight criteria, namely user friendliness, compatibility, quality of transmission, features, bandwidth consumption, awareness, security and privacy, and cost to compare the VC platforms. We provide a novel extension of a very recently developed MCDM method called PROBID with PFN for comparison. The FUCOM method with the actual score measures of PFN is used to derive the criteria weights. We find that users have given more emphasis on the ease of operations, compatibility with multiple systems and devices, quality of the voice and video transmission, and features. While comparing, we notice that Zoom, Microsoft Teams, and Google Meet are preferred by the users. It is interesting to note that WhatsApp comes under the top five bracket because of its wide awareness and availability at less cost. It suggests that only features are not the deciding factors. Wide availability, flexibility, cost, quality of transmission, and ease of use differentiate the VC platforms, which supports our initial proposition. The result of the proposed model shows stability and robustness as evident from the validation test and sensitivity analysis.

The advantage of our proposed PF-FUCOM-PROBID framework are as follows: (a) the model provides a better ability to analyze user experiences regarding the use of $\mathrm{VC}$ tools with PFNs, (b) a lesser number of pairwise comparisons, which, in turn, hold better control over subjective bias and decision inconsistency, (c) ability to work with larger criteria set without losing stability and provision of reasonable robustness, (d) both positive ideal and average solutions are considered, which, in turn, broaden the perspective, and (e) free from rank reversal issue. However, some of the limitations of our analysis are as follows: (a) for a large number of criteria set, FUCOM works equally well, however, PROBID incorporates a little bit of added computational complexity as it requires to formulate a PIS matrix and calculation of the distances of the alternatives from each PIS value, (b) a small group of respondents took part in the study, which invokes the necessity of the model to be tested with a large-scale group decision-making scenario.

Furthermore, we find some scope of extensions for our work. Firstly, one of the observed limitations of the PROBID method is its computational complexity, which may be further tested with larger alternatives and criteria sets. Since PROBID has not been utilized in various kinds of problems, future applications may test its efficacy. It is the second scope. Thirdly, our model may be extended by various other fuzzy numbers, such as SFS, PyFS, and qROFS, to name a few. The fourth point is that other aggregations operators, such as Dombi-Bonferroni aggregation and Hamacher aggregation, among others, may be applied, and the results may be compared. The fifth point is that, in our work, we observe a very limited number of responses. The understanding of the comparative utility of VC tools may be further examined using more heterogeneous groups of a large number of respondents. The sixth point is that we have used only the UX theory. However, consumers also show a varying level of adaptability to various technologies. Hence, the theories, such as UTAUT2 and TAM, may also be utilized for formulating the criteria set. The seventh point is that there are some operational criteria in measurable terms. For example, the category of subscription, number of participants allowed, security options, transmission bandwidth, system requirement, and package-wise cost involvement are some of the operational criteria that may be included to compare the VC tools. In this research work, we have provided a primary level analysis through the lens of the UX theory alone. In an extended work, we plan to incorporate measurable operational criteria and user experience-based attributes to provide a more exhaustive analysis. Nevertheless, though the present paper has some future scopes, we believe that the usefulness and implications of our research do not get undermined because of that. We are hopeful that the present work shall find its relevance in formulating online communication and designing the VC products for facilitating remote teaching-learning in the future.

\section{Data Availability}

The data used to support the findings of this study are included within this article. However, the reader may contact the corresponding author for more details on the data.

\section{Conflicts of Interest}

The authors declare no conflicts of interest.

\section{Authors' Contributions}

All authors contributed equally and significantly in conducting this research work and writing this paper.

\section{References}

[1] D. Serhan, "Transitioning from face-to-face to remote learning: students' attitudes and perceptions of using zoom 
during COVID-19 pandemic," International Journal of Technology in Education and Science, vol. 4, no. 4, pp. 335342, 2020.

[2] J. Crawford, K. Butler-Henderson, J. Rudolph et al., "COVID-19: 20 countries' higher education intra-period digital pedagogy responses," Journal of Applied Learning \& Teaching, vol. 3, no. 1, pp. 1-20, 2020.

[3] C. Zou, W. Zhao, and K. Siau, "COVID-19 pandemic: a usability study on platforms to support eLearning," in International Conference on Human-Computer Interaction, pp. 333-340, Springer, Cham, 2020.

[4] E. Baftiu and K. Pireva Nuci, "The transformation process from in-campus classes into online classes due to the COVID-19 situation--the case of higher education institutions in Kosovo," 2021, https://arxiv.org/abs/2104.03896.

[5] W. Ali, "Online and remote learning in higher education institutes: a necessity in light of COVID-19 pandemic," Higher Education Studies, vol. 10, no. 3, pp. 16-25, 2020.

[6] M. Matulin, Š. Mrvelj, B. Abramović, T. Šoštarić, and M. Čejvan, "User quality of experience comparison between Skype, Microsoft Teams and zoom videoconferencing tools," Lecture Notes of the Institute for Computer Sciences, Social Informatics and Telecommunications Engineering, Springer, Cham, Switzerland, pp. 299-307, 2021.

[7] A.-P. Correia, C. Liu, and F. Xu, "Evaluating videoconferencing systems for the quality of the educational experience," Distance Education, vol. 41, no. 4, pp. 429-452, 2020.

[8] R. Boyatt, M. Joy, C. Rocks, and J. Sinclair, "What (Use) is a MOOC?" in Proceedings of the 2nd International Workshop on Learning Technology for Education in Cloud, pp. 133-145, Springer, Dordrecht, Netherlands, August 2014.

[9] M. M. Archibald, R. C. Ambagtsheer, M. G. Casey, and Michael Lawless, "Using zoom videoconferencing for qualitative data collection: perceptions and experiences of researchers and participants," International Journal of Qualitative Methods, vol. 18, pp. 1-8, 2019.

[10] Q. Wang, C. Huang, and C. Lang Quek, “Students' perspectives on the design and implementation of a blended synchronous learning environment," Australasian Journal of Educational Technology, vol. 34, no. 1, pp. 1-13, 2018.

[11] L. M. Gray, G. Wong-Wylie, G. R. Rempel, and K. Cook, "Expanding qualitative research interviewing strategies: zoom video communications," Qualitative Report, vol. 25, no. 5, pp. 1292-1301, 2020.

[12] O. Parra and M. Fernanda Granda, "Evaluating the meeting solutions used for virtual classes in higher education during the COVID-19 pandemic," in VISIGRAPP (2: HUCAPP), pp. 190-197, 2021.

[13] J. Demuyakor, "Coronavirus (COVID-19) and online learning in higher institutions of education: a survey of the perceptions of Ghanaian international students in China," The Online Journal of Communication and Media Technologies, vol. 10, no. 3, 3 pages, Article ID e202018, 2020.

[14] T. H. Fatani, "Student satisfaction with videoconferencing teaching quality during the COVID-19 pandemic," BMC Medical Education, vol. 20, no. 1, pp. 396-398, 2020.

[15] D. Pal and V. Vanijja, "Perceived usability evaluation of Microsoft Teams as an online learning platform during COVID-19 using system usability scale and technology acceptance model in India," Children and Youth Services Review, vol. 119, Article ID 105535, 2020.

[16] R. Singh and S. Awasthi, "Updated comparative analysis on video conferencing platforms-zoom, Google meet, Microsoft
Teams, WebEx Teams and GoToMeetings," EasyChair: The World for Scientists No, vol. 4026, pp. 1-9, 2020.

[17] H. Ren, Y. Gao, and T. Yang, "A Novel Regret Theory-Based Decision-Making Method Combined with the Intuitionistic Fuzzy Canberra Distance," Discrete Dynamics in Nature and Society, vol. 2020, Article ID 8848031, 9 pages, 2020.

[18] M. Akram, G. Shahzadi, and H. Abdullah Ali, "Decisionmaking framework for an effective sanitizer to reduce COVID-19 under fermatean fuzzy environment," Journal of Mathematics, vol. 2020, Article ID 3263407, 19 pages, 2020.

[19] S. B. Aydemir, S. Yilmaz Gunduz, and Sevcan Yilmaz Gunduz, "Fermatean fuzzy TOPSIS method with dombi aggregation operators and its application in multi-criteria decision making," Journal of Intelligent and Fuzzy Systems, vol. 39, no. 1, pp. 851-869, 2020.

[20] L. A. Zadeh, "Fuzzy sets," Information and Control, vol. 8, no. 3, pp. 338-353, 1965.

[21] K. T. Atanassov, "Intuitionistic fuzzy sets," Fuzzy Sets and Systems, vol. 20, no. 1, pp. 87-96, 1986.

[22] R. R. Yager, "Pythagorean fuzzy subsets," in Proceedings of the 2013 Joint IFSA World Congress and NAFIPS Annual Meeting (IFSA/NAFIPS), pp. 57-61, IEEE, Edmonton, Canada, June 2013.

[23] R. R. Yager, "Pythagorean membership grades in multicriteria decision making," IEEE Transactions on Fuzzy Systems, vol. 22, no. 4, pp. 958-965, 2013.

[24] H. Garg, G. Shahzadi, and M. Akram, "Decision-making analysis based on Fermatean fuzzy Yager aggregation operators with application in COVID-19 testing facility," Mathematical Problems in Engineering, vol. 2020, Article ID 7279027, 16 pages, 2020.

[25] B. Batool, M. Ahmad, S. Abdullah, S. Ashraf, and R. Chinram, "Entropy based Pythagorean probabilistic hesitant fuzzy decision making technique and its application for fog-haze factor assessment problem," Entropy, vol. 22, no. 3, p. $318,2020$.

[26] A. A. Khan, S. Ashraf, S. Abdullah, M. Qiyas, J. Luo, and S. U. Khan, "Pythagorean fuzzy Dombi aggregation operators and their application in decision support system," Symmetry, vol. 11, p. 383, 2019.

[27] S. Ashraf, S. Abdullah, and S. Khan, "Fuzzy decision support modeling for internet finance soft power evaluation based on sine trigonometric Pythagorean fuzzy information," Journal of Ambient Intelligence and Humanized Computing, vol. 12, no. 2, pp. 3101-3119, 2021.

[28] M. J. Khan, P. Kumam, P. Liu, W. Kumam, and S. Ashraf, “A novel approach to generalized intuitionistic fuzzy soft sets and its application in decision support system," Mathematics, vol. 7, no. 8, p. 742, 2019.

[29] M. Qiyas, S. Abdullah, S. Ashraf, and M. Aslam, "Utilizing linguistic picture fuzzy aggregation operators for multipleattribute decision-making problems," International Journal of Fuzzy Systems, vol. 22, no. 1, pp. 310-320, 2020.

[30] M. J. Khan, P. Kumam, S. Ashraf, and W. Kumam, "Generalized picture fuzzy soft sets and their application in decision support systems," Symmetry, vol. 11, p. 415, 2019.

[31] S. Ashraf, T. Mahmood, S. Abdullah, and Q. Khan, "Different approaches to multi-criteria group decision making problems for picture fuzzy environment," Bulletin of the Brazilian Mathematical Society, New Series, vol. 50, no. 2, pp. 373-397, 2019.

[32] H. Garg, Z. Ali, and T. Mahmood, "Interval-Valued Picture Uncertain Linguistic Generalized Hamacher Aggregation Operators and Their Application in Multiple Attribute 
Decision-Making Process," Arabian Journal for Science and Engineering, vol. 46, no. 10, pp. 10153-10170, 2021.

[33] W. Q. Fu, S. G. Li, H. Garg et al., "An Easy-to-Understand Method to Construct Desired Distance-Like Measures," Complexity, vol. 2021, pp. 1-15, 2021.

[34] H. Garg, R. Sujatha, D. Nagarajan, J. Kavikumar, and J. Gwak, "Evidence Theory in Picture Fuzzy Set Environment," Journal of Mathematics, vol. 2021, Article ID 9996281, 8 pages, 2021.

[35] S. Biswas, S. Majumder, D. Pamucar, and S. K. Dawn, "An Extended LBWA Framework in Picture Fuzzy Environment Using Actual Score Measures Application in Social Enterprise Systems," International Journal of Enterprise Information Systems, vol. 17, no. 4, pp. 37-68, 2021.

[36] M. Akram, A. Habib, and J. C. R. Alcantud, "An optimization study based on Dijkstra algorithm for a network with trapezoidal picture fuzzy numbers," Neural Computing \& Applications, vol. 33, pp. 1329-1342, 2021.

[37] S. Ashraf, S. Abdullah, T. Mahmood, F. Ghani, and T. Mahmood, "Spherical fuzzy sets and their applications in multi-attribute decision making problems," Journal of Intelligent and Fuzzy Systems, vol. 36, no. 3, pp. 2829-2844, 2019.

[38] S. Ashraf and S. Abdullah, "Spherical aggregation operators and their application in multiattribute group decisionmaking," International Journal of Intelligent Systems, vol. 34, no. 3, pp. 493-523, 2019.

[39] S. Ashraf, S. Abdullah, and T. Mahmood, "GRA method based on spherical linguistic fuzzy Choquet integral environment and its application in multi-attribute decisionmaking problems," Mathematical Sciences, vol. 12, no. 4, pp. 263-275, 2018.

[40] S. Ashraf, S. Abdullah, and M. Aslam, "Symmetric sum based aggregation operators for spherical fuzzy information: Application in multi-attribute group decision making problem," Journal of Intelligent and Fuzzy Systems, vol. 38, no. 4, pp. 5241-5255, 2020.

[41] S. Ashraf, S. Abdullah, and T. Mahmood, "Spherical fuzzy Dombi aggregation operators and their application in group decision making problems," Journal of Ambient Intelligence and Humanized Computing, vol. 11, no. 7, pp. 2731-2749, 2020.

[42] O. Barukab, S. Abdullah, S. Ashraf, M. Arif, and S. A. Khan, "A new approach to fuzzy TOPSIS method based on entropy measure under spherical fuzzy information," Entropy, vol. 21, no. 12, pp. 1231-12, 2019.

[43] S. Ashraf, S. Abdullah, and L. Abdullah, "Child development influence environmental factors determined using spherical fuzzy distance measures," Mathematics, vol. 7, no. 8, p. 661, 2019.

[44] Y. Jin, S. Ashraf, and S. Abdullah, "Spherical fuzzy logarithmic aggregation operators based on entropy and their application in decision support systems," Entropy, vol. 21, no. 7, pp. 628-7, 2019.

[45] M. Rafiq, S. Ashraf, S. Abdullah, T. Mahmood, and S. Muhammad, "The cosine similarity measures of spherical fuzzy sets and their applications in decision making," Journal of Intelligent and Fuzzy Systems, vol. 36, no. 6, pp. 60596073, 2019.

[46] Z. Wang, G. P. Rangaiah, and X. Wang, "Preference ranking on the basis of ideal-average distance method for multicriteria decision-making," Industrial \& Engineering Chemistry Research, vol. 60, no. 30, pp. 11216-11230, 2021.
[47] D. Pamučar, Ž. Stević, and S. Sremac, "A new model for determining weight coefficients of criteria in MCDM models: full consistency method (FUCOM)," Symmetry, vol. 10, p. 393, 2018.

[48] F. D. Davis, "Perceived usefulness, perceived ease of use, and user acceptance of information technology," MIS Quarterly, vol. 13, no. 3, pp. 319-340, 1989.

[49] H. Fazlollahtabar, A. Smailbašić, A. Smailbašić, and Ž. Stević, "FUCOM method in group decision-making: selection of forklift in a warehouse," Decision Making: Applications in Management and Engineering, vol. 2, no. 1, pp. 49-65, 2019.

[50] E.. Durmić, "Evaluation of criteria for sustainable supplier selection using FUCOM method," Operational Research in Engineering Sciences: Theory and Applications, vol. 2, pp. 91-107, 2019.

[51] E. Durmić, Ž. Stević, P. Chatterjee, M. Vasiljević, and M. Tomašević, "Sustainable supplier selection using combined FUCOM-Rough SAW model," Reports in mechanical engineering, vol. 1, pp. 34-43, 2020.

[52] D. Pamučar and A. Janković, "The application of the hybrid interval rough weighted Power-Heronian operator in multicriteria decision making," Operational Research in Engineering Sciences: Theory and Applications, vol. 3, pp. 54-73, 2020.

[53] Ž. Erceg, V. Starčević, D. Pamučar, G. Mitrović, Ž. Stević, and S. Žikić, "A new model for stock management in order to rationalize costs: $\mathrm{ABC}-\mathrm{FUCOM}$-interval rough CoCoSo model," Symmetry, vol. 11, no. 12, pp. 1527-12, 2019.

[54] I. Badi and M. Kridish, "Landfill site selection using a novel FUCOM-CODAS model: a case study in Libya," Scientific African, vol. 9, Article ID e00537, 2020.

[55] M. Yazdani, P. Chatterjee, D. Pamucar, and S. Chakraborty, "Development of an integrated decision making model for location selection of logistics centers in the Spanish autonomous communities," Expert Systems with Applications, vol. 148, Article ID 113208, 2020.

[56] Ž. Stević and N. Brković, "A novel integrated FUCOMMARCOS model for evaluation of human resources in a transport company," Logistics, vol. 4, no. 1, pp. 1-14, 2020.

[57] M. C. Ong, Y. T. Leong, Y. K. Wan, and I. M. L. Chew, "Multi-objective optimization of integrated water system by FUCOM-VIKOR approach," Process Integration and Optimization for Sustainability, vol. 5, no. 1, pp. 43-62, 2021.

[58] F. Feizi and S. Farhadi, "FUCOM-MOORA and FUCOMMOOSRA: new MCDM-based knowledge-driven procedures for mineral potential mapping in greenfields," $S N$ Applied Sciences, vol. 3, no. 3, pp. 1-19, 2021.

[59] Q. Cao and S. Esangbedo, "Grey SWARA-FUCOM weighting method for contractor selection MCDM problem: a case study of floating solar panel energy system installation," Energies, vol. 12, no. 13, pp. 2481-13, 2019.

[60] D. Pamucar, M. Deveci, F. Canitez, and D. Bozanic, "A fuzzy Full Consistency Method-Dombi-Bonferroni model for prioritizing transportation demand management measures," Applied Soft Computing, vol. 87, Article ID 105952, 2020.

[61] D. Bozanic, D. Tešić, and A. Milić, "Multicriteria decision making model with Z-numbers based on FUCOM and MABAC model," Decision Making: Applications in Management and Engineering, vol. 3, no. 2, pp. 19-36, 2020.

[62] M. A. Sofuoğlu, "Fuzzy applications of FUCOM method in manufacturing environment," Politeknik Dergisi, vol. 23, no. 1, pp. 189-195, 2020. 
[63] D. Pamucar and F. Ecer, "Prioritizing the weights of the evaluation criteria under fuzziness: the fuzzy full consistency method - fucom-f," Facta Universitatis - Series: Mechanical Engineering, vol. 18, no. 3, pp. 419-437, 2020.

[64] M. Simić, Jelena, Ž. Stević, V. Bogdanović, M. Subotić, and A. Mardani, "A novel CRITIC-Fuzzy FUCOM-DEA-Fuzzy MARCOS model for safety evaluation of road sections based on geometric parameters of road," Symmetry, vol. 12, no. 2020, 12 pages, 2006.

[65] B. C. Cuong and V. Kreinovich, "Picture fuzzy sets," Journal of Computer Science and Cybernetics, vol. 30, no. 4, pp. 409-420, 2014.

[66] B. C. Cuong and V. Kreinovich, "Picture Fuzzy Sets-a new concept for computational intelligence problems," in Proceedings of the 2013 Third World Congress on Information and Communication Technologies (WICT 2013), pp. 1-6, IEEE, Hanoi, Vietnam, December 2013.

[67] C. Wang, X. Zhou, H. Tu, and S. Tao, "Some geometric aggregation operators based on picture fuzzy sets and their application in multiple attribute decision making," Italian Journal of Pure and Applied Mathematics, vol. 37, pp. 477-492, 2017.

[68] L. H. Son, "Measuring analogousness in picture fuzzy sets: from picture distance measures to picture association measures," Fuzzy Optimization and Decision Making, vol. 16, no. 3, pp. 359-378, 2017.

[69] X.-G. Xu, H. Shi, D.-H. Xu, and H.-C. Liu, "Picture fuzzy Petri nets for knowledge representation and acquisition in considering conflicting opinions," Applied Sciences, vol. 9, no. 5 , p. $983,2019$.

[70] C. B. Cuong and H. L. Son, "Some selected problems of modern soft computing," Expert Systems with Applications, vol. 42, pp. 51-66, 2015.

[71] L. H. Son, "Generalized picture distance measure and applications to picture fuzzy clustering," Applied Soft Computing, vol. 46, pp. 284-295, 2016.

[72] A. Si, S. Das, and S. Kar, "An approach to rank picture fuzzy numbers for decision making problems," Decision Making: Applications in Management and Engineering, vol. 2, no. 2, pp. 54-64, 2019.

[73] M. Wende, S. Bulut, Tim Giese, and R. Anderl, "Online lectures-strategies for applying advanced digital media for future higher education," in Proceedings of the 2020 IEEE International Conference on Teaching, Assessment, and Learning for Engineering (TALE), pp. 311-318, IEEE, December 2020.

[74] K. Tremblay, D. Lalancette, and D. Roseveare, "Assessment of Higher Education Learning Outcomes: Feasibility Study Report, Volume 1-Design and Implementation," Paris, France: Organisation for Economic Co-operation and Development, https://www.oecd.org/education/skills-beyondschool/AHELOFSReportVolume1.pdf, 2012.

[75] ISO 9241-210, Ergonomics of Human-System Interaction Part 210: Human-Centered Design for Interactive Systems, ISO, Geneva, Switzerland, 2010.

[76] J. Park, S. H. Han, H. K. Kim, Y. Cho, and W. Park, "Developing elements of user experience for mobile phones and services: survey, interview, and observation approaches," Human Factors and Ergonomics in Manufacturing \& Service Industries, vol. 23, no. 4, pp. 279-293, 2013a.

[77] J. Park, S. H. Han, H. K. Kim, S. Oh, and H. Moon, "Modeling user experience: a case study on a mobile device," International Journal of Industrial Ergonomics, vol. 43, no. 2, pp. 187-196, 2013.
[78] T. Baekdal, The Battle between Usability and User-Experience, https://www.baekdal.com/articles/usabilty-vs-userexperience-battle, 2006.

[79] J. Brade, M. Lorenz, M. Busch, N. Hammer, M. Tscheligi, and P. Klimant, "Being there again - presence in real and virtual environments and its relation to usability and user experience using a mobile navigation task," International Journal of Human-Computer Studies, vol. 101, pp. 76-87, 2017.

[80] S. Caboral, M. Whetsell, M. V. Whetsell, L. S. Evangelista, B. Cypress, and D. Nickitas, "U.S.A.B.I.L.I.T.Y. Framework for Older Adults," Research in Gerontological Nursing, vol. 8, no. 6, pp. 300-306, 2015.

[81] J. Spool, "The difference between usability and user experience," User Interface Engineering, https://archive.uie.com/ brainsparks/2007/03/16/the-difference-between-usabilityand-user-experience/, 2007.

[82] S.. Biswas, "Implications of industry 4.0 vis-à-vis lean SixSigma: A multi-criteria group decision approach," in Proceedings of the JD Birla International Management Conference on "Strategic Management in Industry, Kolkata, India, September 2019.

[83] M. G. Kendall, Rank Correlation Methods, Griffin, Greece, Egypt, 1948.

[84] Z. Turskis, J. Antuchevičienè, V. Keršulienè, and G. Gaidukas, "Hybrid group MCDM model to select the most effective alternative of the second runway of the airport," Symmetry, vol. 11, no. 6, p. 792, 2019.

[85] S. Jovčić, V. Simić, P. Průša, and M. Dobrodolac, "Picture fuzzy ARAS method for freight distribution concept selection," Symmetry, vol. 12, no. 7, p. 1062, 2020.

[86] S. Zhang, G. Wei, H. Gao, C. Wei, and Y. Wei, "EDAS method for multiple criteria group decision making with picture fuzzy information and its application to green suppliers selections," Technological and Economic Development of Economy, vol. 25, no. 6, pp. 1123-1138, 2019.

[87] S. Laha and S. Biswas, "A hybrid unsupervised learning and multi-criteria decision making approach for performance evaluation of Indian banks," Accounting, vol. 5, no. 4, pp. 169-184, 2019.

[88] I. Ghosh and S. Biswas, "A novel framework of ERP implementation in Indian SMEs: Kernel principal component analysis and intuitionistic Fuzzy TOPSIS driven approach," Accounting, vol. 3, no. 2, pp. 107-118, 2017.

[89] P. K. Pramanik, D. Dutta, S. Biswas, S. Pal, D. Marinković, and P. Choudhury, "A Comparative Analysis of MultiCriteria Decision-Making Methods for Resource Selection in Mobile Crowd Computing," Symmetry, vol. 13, no. 9, p. 1713, 2021.

[90] S. Biswas, S. Majumder, and S. Kumar Dawn, "Comparing the Socioeconomic Development of G7 and BRICS Countries and Resilience to COVID-19: An Entropy-MARCOS Framework," Business Perspectives and Research, vol. 18, pp. 1-18, 2021.

[91] S. Gupta, G. Bandyopadhyay, S. Biswas, and A. Upadhyay, "A hybrid machine learning and dynamic nonlinear framework for determination of optimum portfolio structure," in Innovations in Computer Science and Engineering, pp. 437-448, Springer, Singapore, 2019.

[92] S. Biswas, G. Bandyopadhyay, B. Guha, and M. Bhattacharjee, "An ensemble approach for portfolio selection in a multi-criteria decision making framework," Decision Making: Applications in Management and Engineering, vol. 2, no. 2, pp. 138-158, 2019. 
[93] S. Biswas, "Measuring performance of healthcare supply chains in India: A comparative analysis of multi-criteria decision making methods," Decision Making: Applications in Management and Engineering, vol. 3, no. 2, pp. 162-189, 2020.

[94] I. Ghosh and S. Biswas, "A comparative analysis of multicriteria decision models for ERP package selection for improving supply chain performance," Asia-Pacific Journal of Management Research and Innovation, vol. 12, no. 3-4, pp. 250-270, 2016.

[95] P. Karmakar, P. Dutta, and S. Biswas, "Assessment of mutual fund performance using distance based multi-criteria decision making techniques-An Indian perspective," Research bulletin, vol. 44, pp. 17-38, 2018.

[96] D. Pamučar, M. Zižović, S. Biswas, and D. Božanić, "A new logarithm methodology of additive weights (LMAW) for multi-criteria decision-making: application in logistics," Facta Universitatis - Series: Mechanical Engineering, vol. 19, pp. 361-380, 2021.

[97] Y. W. Yang and Y. Y. He, "Decision-Making Method Based on Picture Fuzzy Sets and Its Application in College Scholarship Evaluation," Decision-Making, vol. 2, no. 9, pp. 48-57, 2019.

[98] D. Pamučar and G. Ćirović, "The selection of transport and handling resources in logistics centers using Multi-Attributive Border Approximation area Comparison (MABAC)," Expert Systems with Applications, vol. 42, no. 6, pp. 30163028, 2015.

[99] I. Mukhametzyanov and D. Pamucar, "A sensitivity analysis in MCDM problems: A statistical approach," Decision making: Applications in Management and Engineering, vol. 1, pp. 51-80, 2018.

[100] D. Pamucar, D. Bozanic, and A. Randjelovic, "Multi-criteria decision making: An example of sensitivity analysis," Serbian journal of management, vol. 12, no. 1, pp. 1-27, 2017.

[101] S. Biswas and Om P. Anand, "Logistics Competitiveness Index-Based Comparison of BRICS and G7 Countries: An Integrated PSI-PIV Approach," IUP Journal of Supply Chain Management, vol. 17, no. 2, pp. 32-57, 2020.

[102] S. Biswas and D. Pamucar, "Combinative distance based assessment (CODAS) framework using logarithmic normalization for multi-criteria decision making," Serbian Journal of Management, vol. 16, no. 2, pp. 321-340, 2021. 